\title{
RESÍDUOS DE DELTAMETRINA E DE CARBARIL EM DOIS SISTEMAS DE CONDUÇÃO DA CULTURA DE TOMATE ESTAQUEADO (Lycopersicon esculentum Mill) E SUA EFICIÊNCIA NO CONTROLE DA BROCA-PEQUENA-DO-FRUTO Neoleucinodes elegantalis (Guenée, 1854) (Lepidoptera: Crambidae)
}

STELLA PACHECO LOMBARDI DE CARVALHO 


\title{
RESÍDUOS DE DELTAMETRINA E DE CARBARIL EM DOIS SISTEMAS DE CONDUÇÃO DA CULTURA DE TOMATE ESTAQUEADO (Lycopersicon esculentum Mill) E SUA EFICIÊNCIA NO CONTROLE DA BROCA-PEQUENA-DO-FRUTO Neoleucinodes elegantalis (Guenée, 1854) (Lepidoptera: Crambidae)
}

\section{STELLA PACHECO LOMBARDI DE CARVALHO Engenheiro Agrônomo}

Orientador: Prof. Dr. GILBERTO CASADEI DE BAPTISTA

\author{
Dissertação apresentada à Escola Superior \\ de Agricultura "Luiz de Queiroz", \\ Universidade de São Paulo, para obtenção \\ do título de Mestre em Ciências, Área de \\ Concentração: Entomologia
}

PIRACICAB A

Estado de São Paulo - Brasil

Dezembro - 2003 
Dados Internacionais de Catalogação na Publicação (CIP) DIVISÃO DE BIBLIOTECA E DOCUMENTAÇÃO - ESALQIUSP

Carvalho, Stella Pacheco Lombardi de

Resíduos de deltametrina e de carbaril em diferentes sistemas de condução na cultura do tomate estaqueado (Lycopersicon esculentum Mill) e eficiência no controle da broca-pequena-dofruto (Neoleucinodes elegantalis) (Guenée: 1854) (Lepidoptera: Crambidae) / Stella Pacheco Lombardi de Carvalho. - Piracicaba, 2004.

51 p.: il.

Dissertação (mestrado) - - Escola Superior de Agricultura Luiz de Queiroz, 2003.

Bibliografia.

1. Análise do solo 2. Broca-pequena-do-fruto 3 . Inseticidas 4. Resíduos de pesticidas em plantas 5. Tomate I. Título

CDD 635.642

\section{"Permitida a cópia total ou parcial deste documento, desde que citada a} fonte - O autor" 
Ao meu marido, Guilherme e meu filho, Raphael por me proporcionarem sempre os melhores momentos da minha vida;

Aos meus pais, Francisco e Regina pela dedicação em todas as fases da minha vida;

Às minhas queridas irmãs Simone, Marina e Beatriz pelo carinho, amizade e companheirismo;

Aos queridos Nelson e Vera por toda ajuda sempre;

MINHA HOMENAGEM E AGRADECIMENTO

Aos queridos, Guilherme e Raphael, DEDICO 


\section{AGRADECIMENTOS}

A Deus, porque sem Ele nada seria possível;

Ao Prof. Dr. Gilberto Casadei de Baptista, por toda orientação e confiança durante o curso.

A todos os professores e funcionários do Departamento de Entomologia, Fitopatologia e Zoologia Agrícola da ESALQ/USP pela oportunidade e contribuição na realização do mestrado.

Ao Dr. Luiz Roberto Pimentel Trevizan pela inestimável ajuda, amizade, confiança e apoio durante todo o trabalho.

A FEALQ, que através do Projeto Fundo de Apoio ao Ensino e à Pesquisa na Área de Resíduos de Pesticidas (FAEPARP 2818-5) concedeu a bolsa de estudos.

Aos amigos e estagiários do Laboratório de Resíduos de Pesticidas e Análises Cromatográficas do Departamento de Entomologia, Fitopatologia e Zoologia Agrícola da ESALQ/USP.

Ao colega Engo Agrô André Andrade Franco pelo auxílio durante todo o trabalho. 
Ao Eng ${ }^{0}$ Agro․ Renato Agnelo da Silva pela concessão da área para montagem do campo experimental.

A amiga Dra. Marinéia de Lara Haddad pela ajuda nas análises estatísticas.

Aos funcionários da Biblioteca Central da ESALQ/USP, pelo auxílio na elaboração deste trabalho.

A todas a pessoas que, direta ou indiretamente contribuíram para a realização desse trabalho, o meu muito obrigada. 


\section{SUMÁRIO}

Página

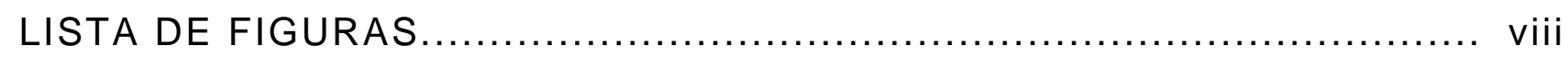

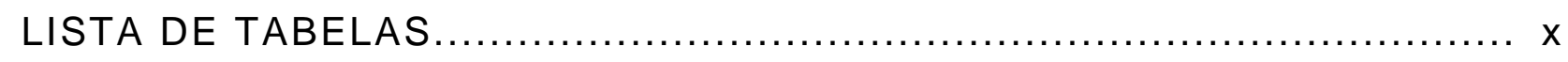

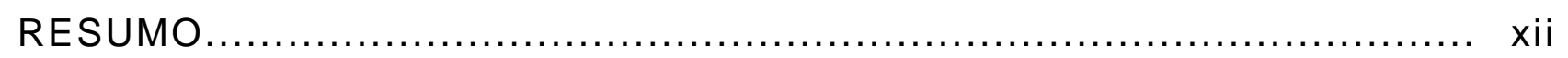

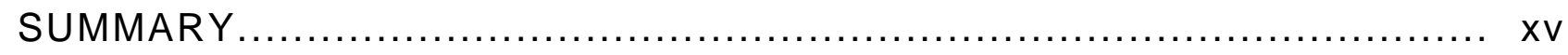

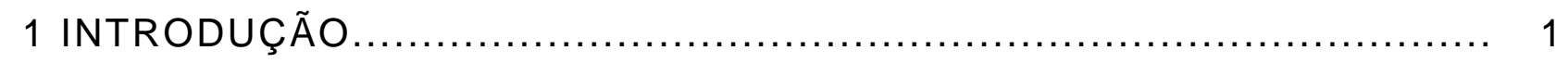

2 REVISÃO DE LITERATURA........................................... 4

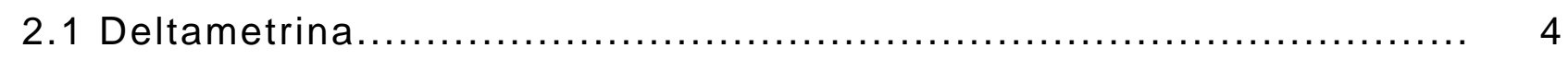

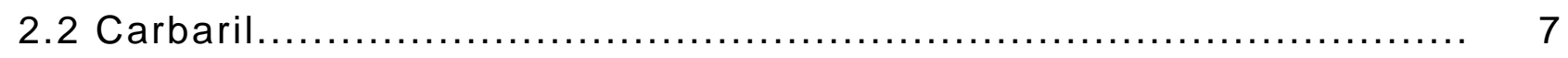

2.3 Descrição, Importância e Controle da broca-pequena-do-fruto......... 10

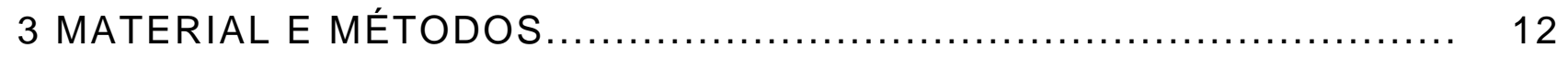

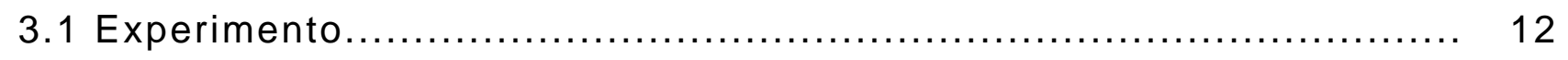

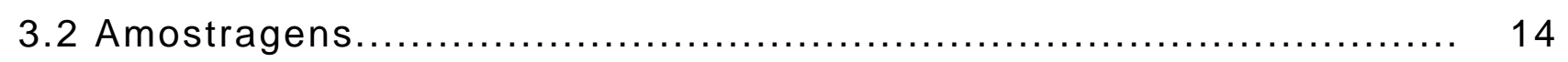


3.3 Limites de quantificação, porcentagens de recuperação e descrição do método de análise de resíduos de deltametrina e de carbaril em amostras de fruto, folha e solo

3.3.1 Método para análises de resíduos de deltametrina e de carbaril em fruto, folha e solo

3.3.1.1 Fruto e folha....................................................... 15

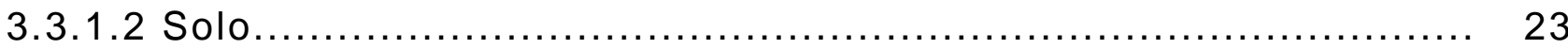

3.4 Avaliação da infestação da broca-pequena-do-fruto..................... 24

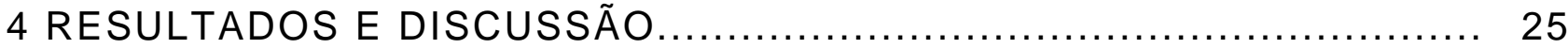

4.1 Limites de quantificação e porcentagens de recuperação dos métodos de análises de resíduos de deltametrina e de carbaril em

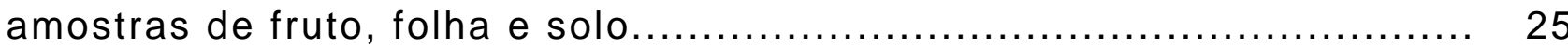

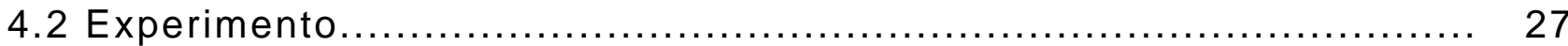

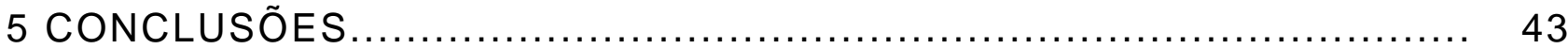

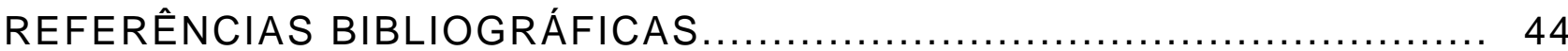




\section{LISTA DE FIGURAS}

Página

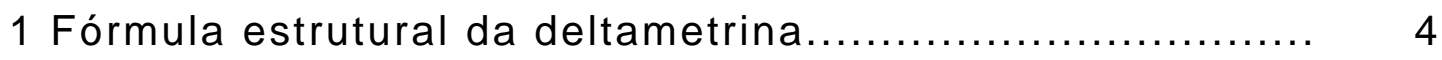

2 Fórmula estrutural do carbaril............................. 8

3 Cromatograma de padrão de deltametrina................... 27

4 Cromatograma de amostra de fruto (deltametrina)

tratamento linha simples.............................. 28

5 Cromatograma de amostra de folha (deltametrina)

tratamento linha simples................................. 28

6 Cromatograma de amostra de solo (deltametrina) tratamento linha simples............................................ 29

7 Cromatograma padrão de carbaril........................... 29

8 Cromatograma de amostra de fruto (carbaril) tratamento

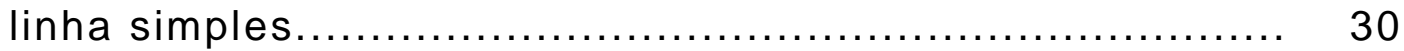

9 Cromatograma de amostra de folha (carbaril) tratamento linha simples.............................................. 30

10 Cromatograma de amostra de solo (carbaril) tratamento linha simples............................................ 31 
11 Fenograma (Distância Média e Método de Ligação Simples) para os parâmetros: resíduo, peso, altura, diâmetro e número de frutos brocados e

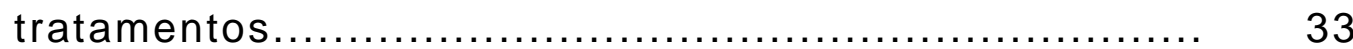




\section{LISTA DE TABELAS}

Página

1 Propriedades físicas e químicas da deltametrina.............. 5

2 Propriedades físicas e químicas do carbaril................... 8

3 Condições climáticas durante a realização do experimento,

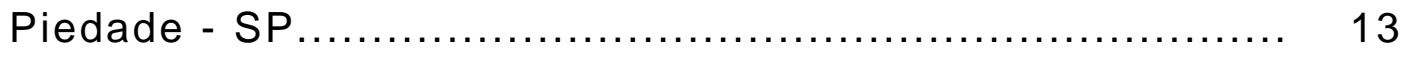

4 Porcentagens (\%) de recuperação de resíduos de deltametrina e de carbaril em amostras fortificadas de frutos

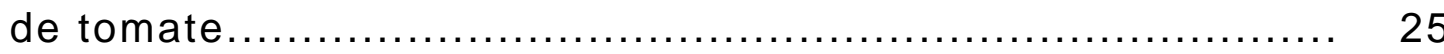

5 Porcentagens (\%) de recuperação de resíduos de deltametrina e de carbaril em amostras fortificadas de folhas

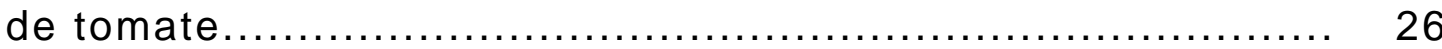

6 Porcentagens (\%) de recuperação de resíduos de deltametrina e de carbaril em amostras fortificadas de solo.

7 Média de resíduos dos inseticidas, peso, altura, diâmetro e número de frutos brocados colhidos um dia antes da última aplicação

8 Correlação (Pearson) e respectivas probabilidades (Bonferroni) entre os parâmetros: resíduo, peso, altura, diâmetro e número de frutos brocados 
10 Resíduos de deltametrina em tomate (frutos), nos tratamentos linha simples e linha dupla. Piedade-SP .... 34

11 Resíduos de carbaril em tomate (frutos), nos tratamentos linha simples e linha dupla. Piedade - SP................ 35

12 Resíduos de deltametrina em tomate (folhas), nos tratamentos linha simples e linha dupla. Piedade-SP ..... 37

13 Resíduos de carbaril em tomate (folhas), nos tratamentos linha simples e linha dupla. Piedade-SP ................. 38

14 Resíduos de deltametrina no solo, nos tratamentos linha simples e linha dupla. Piedade-SP ...................... 40

15 Resíduos de carbaril no solo, nos tratamentos linha simples e linha dupla. Piedade-SP 


\section{RESÍDUOS DE DELTAMETRINA E DE CARBARIL EM DOIS SISTEMAS DE CONDUÇÃO DA CULTURA DE TOMATE ESTAQUEADO (Lycopersicon esculentum Mill) E SUA EFICIÊNCIA NO CONTROLE DA BROCA-PEQUENA-DO-FRUTO, Neoleucinodes elegantalis (Guenée, 1854) \\ (Lepidoptera: Crambidae)}

Autora: STELLA PACHECO LOMBARDI DE CARVALHO Orientador: Prof. Dr. GILBERTO CASADEI DE BAPTISTA

\section{RESUMO}

O objetivo deste estudo foi avaliar os inseticidas deltametrina e carbaril, de modo a abranger seus resíduos em dois sistemas de condução da cultura de tomate estaqueado (linha dupla, plantio comercial e linha simples, plantio experimental) e sua eficiência no controle da broca-pequena-do-fruto, a determinação dos resíduos nos substratos: frutos (visando à proteção à saúde pública), folhas e solo (como uma possível fonte de contaminação ambiental), a comparação dos níveis de resíduos encontrados nesses diferentes sistemas de condução, o controle 
obtido com os dois inseticidas e sistemas de condução e a comparação dos níveis de resíduos dos frutos com os LMRs (Limites Máximo de Resíduo) e intervalo de segurança estabelecidos pela legislação brasileira. $O$ experimento foi conduzido no Município de Piedade, no Estado de São Paulo, Brasil. Consistiu em cinco tratamentos: (1) nove aplicações de deltametrina (Decis 25 CE) no plantio linha simples, (2) nove aplicações de carbarill (Sevin 480 SC) no plantio linha simples, (3) nove aplicações de deltametrina (Decis 25 CE) em linha dupla, (4) nove aplicações de carbaril (Sevin 480 SC) no plantio linha dupla e (5) controle. A primeira aplicação foi feita no início da fase de maturação do fruto e as seguintes em intervalos subseqüentes de 7 dias. As amostras de frutos foram colhidas com (-1), zero, 3, 5 e 10 dias após a última aplicação. As amostras de folha e solo foram coletadas com (-1), zero, $1,3,10$ e 20 dias após a última aplicação. O método analítico consistiu na extração dos resíduos com acetato de etila, limpeza dos extratos em cromatografia de permeação em gel (GPC), e determinação quantitativa em cromatógrafo de gás equipado com detector de captura de elétrons (GLC/ECD) (deltametrina) e em cromatógrafo de gás equipado com detector seletivo de massas (GLC/MSD). Os resultados mostraram que os resíduos de deltametrina nos frutos no plantio comercial estavam abaixo de seu LMR ao final do intervalo de segurança; o mesmo não ocorreu com o carbaril que nos dois sistemas de condução, apresentou resíduos superiores ao seu LMR. Os resíduos maiores foram encontrados nas folhas, para ambos os inseticidas, constituindo assim, estas, uma possível fonte de contaminação ambiental. Os resíduos encontrados no solo foram baixos, no caso da deltametrina se aproximaram dos valores encontrados para o fruto e os de carbaril foram ainda menores que 
os do fruto, mostrando um baixo escorrimento da calda de saturação e conseqüentemente, um baixo potencial de contaminação do solo. O plantio experimental (linha simples) apresentou resíduos sempre maiores que o plantio comercial (linha dupla), sendo, em conseqüência, melhor o controle da praga nesses tratamentos. 


\section{RESIDUES OF DELTAMETHRIN AND CARBARYL IN TWO CULTIVATION SYSTEMS OF STAKED TOMATO CROP (Lycopersicon esculentum MilI) AND THEIR EFFICIENCY IN THE CONTROL OF THE FRUIT SMALL BORER Neoleucinodes elegantalis (Guenée: 1854) (Lepidoptera: Crambidae)}

Author: STELLA PACHECO LOMBARDI DE CARVALHO Adviser: Prof. Dr. GILBERTO CASADEI DE BAPTISTA

\section{SUMMARY}

The objective of this study was to evaluate the insecticides deltamethrin and carbaryl, in order to study their residues, in two cultivation systems of staked tomato crop: experimental cultivation (single line) and commercial cultivation (double line) and their efficiency in the control of the fruit small borer, Neouleucinodes elegantalis (Guenée, 1854) (Lepidoptera: Crambidae), the determination of the residues in fruits (aiming the protection of public health), leaves and soil (like a possible source 
of environmental contamination), the comparison of residues found in these two different systems of cultivation, the control achieved with both insecticides and systems of cultivation and the comparison of the residues in fruits with the MRLs (Maximum Residue Levels) and safety intervals established by Brazilian legislation. The experiment was conducted Piedade County in the State of São Paulo, Brazil. It consisted of five treatments: (1) nine applications of deltamethrin (Decis $25 \mathrm{CE}$ ) in single line, (2) nine applications of carbaryl (Sevin 480 SC) in single line, (3) nine applications of deltamethrin (Decis $25 \mathrm{CE}$ ) in double line, (4) nine applications of carbaryl (Sevin $480 \mathrm{SC}$ ) in double line and (5) control. The first application was made at the begining of the fruit maturation stage, and the following ones in 7 days period scheduled. Fruit samples were collected one day before the last application ( -1 day) and zero, 3, 5 and 10 days after the last application. Leaf and soil samples were collected one day before the last application ( -1 day) and zero, 1, 3, 10 and 20 days after the last application. The analytical method consisted by extraction of residues with ethyl acetate, clean-up of the extracts by gel permeation chromatograph (GPC), and quantitative determination by gas chromatograph equipped with electron capture detector (GLC/ECD) (deltamethrin) and by gas chromatograph equipped with mass selective detector (GLC/MSD). The results showed that deltamethrin residues in fruits from commercial cultivation system (double line) were below MRL at the end of safety interval; as for carbaril residues they were above $M R L$ in fruits from both cultivation systems. Higher residues were found on leaves, for both insecticides, being considered this as a possible source of environmental contamination. Soil residues were lower; as for deltamethrin the levels were similar to fruit, but for carbaril they were lower in as compared to fruits showing low drift from the 
saturated foliage and consequently, low potential of soil contamination. The experimental cultivation system (single line) always showed higher residue levels for both insecticides than the commercial one (double line), being, in consequence, better the insect pest control in these treatments. 


\section{INTRODUÇÃo}

O tomate é uma hortaliça originária da América do Sul (Norte do Chile e Equador), sendo levada para a América Central pelos índios e para outras partes do mundo pelos viajantes europeus, no século $X V$, utilizada como ornamentação e tendo apenas somente no século XIX passado a ser consumido como alimento (Miranda et al., 1995).

No Brasil foi introduzido pelos imigrantes italianos no início do século XX e foi desenvolvida pelos agricultores japoneses, mas apenas para o consumo "in natura".

A produção mundial de tomate supera 70 milhões de toneladas/ano, sendo considerada uma das hortaliças mais cultivadas e de maior importância em todo o mundo, não só em produção como em valor econômico, pois a cultura industrializada emprega grande contingente de mão-de-obra, estando diariamente na dieta alimentar de boa parte da população (Minami \& Haag, 1989).

O Brasil é um dos principais produtores mundiais e o Estado de São Paulo contribui com cerca de $21 \%$ desta produção. De acordo com as informações de safra, em 2002 o Estado de São Paulo produziu cerca de 766.000 toneladas em área cultivada de 12 mil hectares (AGRIANUAL, 2002).

A cultura do tomate exige grande quantidade de mão-de-obra, adubação pesada, investimentos fitossanitários importantes, com pulverizações freqüentes desde a emergência até a colheita, resultando em alto custo da produção. Para o controle de pragas e doenças empregam-se pesticidas de maior ou menor toxicidade comparativa. Por outro lado, pode ocorrer a 
persistência desses agrotóxicos nos substratos tratados na forma de resíduos tóxicos, cujo consumo representa risco potencial à saúde dos consumidores.

O uso freqüente dos agrotóxicos e os riscos causados ao meio ambiente, à saúde dos consumidores e dos trabalhadores rurais tem gerado grandes preocupações na população que tem buscado cada vez mais, produtos com menores quantidades de seus resíduos. Na década de oitenta os organoclorados foram proibidos em função de sua alta persistência no meio ambiente, baseada em uma série de trabalhos que mostravam a possibilidade de sua bioconcentração. Desse modo, atualmente, buscam-se produtos que apresentem baixos impactos no meio ambiente.

A facilidade de uso, a rápida ação e a economicidade e eficiência dos pesticidas na solução dos problemas agrícolas, faz com que, mundialmente, o Brasil venha se posicionando como um mercado promissor e atrativo para a indústria de agrotóxicos. Em vendas, em quase dez anos, o mercado brasileiro de pesticidas mais do que dobrou em termos nominais. Enquanto em 1992, a receita obtida pelas empresas desses insumos se aproximou de US\$ 1 bilhão (US\$ 947,39 milhões), em 2000 alcançou os US\$ 2,5 bilhões. Atualmente, o Brasil é o $3^{\circ}$ maior mercado mundial, precedido apenas pelos EUA e Japão (Cardoso, 2002).

O tomate é uma hortaliça muito consumida "in natura", muito utilizada na indústria para a produção de suco, purê e extrato, sendo grande parte destinada à exportação, o que faz necessária a determinação de níveis de resíduos e intervalos de segurança para que assim esses produtos sejam aceitos nacional e internacionalmente.

Buscando alternativas para uma melhor utilização desses produtos químicos, na tentativa de diminuir os resíduos deixados nos produtos agrícolas e compartimentos da cultura que potencialmente podem se tornar fontes de contaminação ambiental e causar riscos à saúde pública, realizou-se a presente pesquisa, que teve como objetivo geral: a avaliação dos resíduos dos inseticidas carbaril e deltametrina em dois sistemas de condução diferentes 
(linha dupla e simples) de produção de tomate estaqueado e sua eficiência no controle da broca-pequena-do-fruto Neoleucinodes elegantalis (Guenée, 1854) (Lepidoptera: Crambidae)). Tem ainda como objetivos específicos:

a) a determinação dos resíduos nos substratos: frutos (visando à proteção à saúde pública), folhas e solo (como uma possível fonte de contaminação ambiental);

b) a comparação dos níveis de resíduos nos diferentes sistemas de condução (linha dupla: plantio comercial e linha simples: plantio experimental);

c) o controle da broca-pequena-do-fruto obtido com os dois inseticidas nos dois sistemas de condução;

d) a comparação dos níveis de resíduos dos frutos com os LMRs (Limites Máximo de Resíduos) e intervalos de segurança estabelecidos pela legislação. 


\section{REVISÃO DE LITERATURA}

O uso de agrotóxicos em hortaliças encontra seu maior mercado na cultura de tomate com gastos anuais de cerca de 40-65 milhões de dólares no período de 1997-2001, sendo esta olerícola a que apresenta o maior gasto relativo dentre as principais culturas agrícolas com aproximadamente 700-1000 dólares/ha. A ordem de importância, segundo as classes de produtos, destaca, em primeiro lugar a dos fungicidas, seguida pela dos inseticidas e, por fim, os herbicidas.

\subsection{Deltametrina}

A deltametrina é um inseticida do grupo químico dos piretróides, conhecido quimicamente como (S)-alfa-ciano-m-fenoxibenzil (1R, 3R)-3-(2,2 dibromovinil)-2,2-dimetil ciclopropano carboxilato (Andrei, 1996); sua fórmula estrutural é: (Tomlin, 1995).<smiles>C[C@H](OC(=O)[C@H]1[C@@H](C=C(Br)Br)C1(C)C)c1cccc(Oc2ccccc2)c1</smiles>

Figura 1 - Fórmula estrutural da deltametrina 
Tabela 1. Propriedades físicas e químicas da deltametrina

\begin{tabular}{ll}
\hline \multicolumn{1}{c}{ Parâmetros } & \multicolumn{1}{c}{ Valores } \\
\hline fórmula química & $\mathrm{C}_{22} \mathrm{H}_{19} \mathrm{Br}_{2} \mathrm{NO}_{3}$ \\
peso molecular & 505,2 \\
ponto de fusão & $100-102^{\circ} \mathrm{C}$ \\
coeficiente de partição $\left(\mathrm{K}_{\mathrm{ow}}\right)$ & $4,6\left(25^{\circ} \mathrm{C}\right)$ \\
solubilidade em água & $<0,2 \mu \mathrm{gg} / \mathrm{L}\left(25^{\circ} \mathrm{C}\right)$ \\
pressão de vapor $\left(25^{\circ} \mathrm{C}\right)$ & $1,24 \times 10^{-5} \mathrm{mPa}$ \\
\hline
\end{tabular}

Fonte: Tomlin (1995)

Possui $\mathrm{DL}_{50}$ aguda oral de $135 \mathrm{mg} \cdot \mathrm{kg}^{-1}$ para rato albino, para cães é > $300 \mathrm{mg} \cdot \mathrm{kg}^{-1} ; \mathrm{DL}_{50}$ aguda dérmica $>2.000 \mathrm{mg} \cdot \mathrm{kg}^{-1}$ para ratos (Tomlin, 1995). No Brasil, é comercializado com vários nomes entre os quais: Decis $25 \mathrm{CE}$, Decis Tab, estando registrado em algumas formulações para uso em mais de 30 culturas, entre as quais a de tomate, nesta, com LMR de $0,03 \mathrm{mg} \cdot \mathrm{kg}^{-1}$ (ppm) e intervalo de segurança de 3 dias (foliar) (Agência Nacional de Vigilância Sanitária, 2003a).

Balwinder et al. (1989) estudaram resíduos dos inseticidas piretróides cipermetrina, fenvalerate e deltametrina em tomate, utilizando a dose recomendada e o dobro da dose recomendada (50 e $100 \mathrm{~g}$ i. a.ha ${ }^{-1}$ para cipermetrina e fenvalerate, e 12 e $24 \mathrm{~g}$ de i. a.ha ${ }^{-1}$ para deltametrina) em condições sub-tropicais. As pulverizações começaram quando cerca de 50\% das plantas encontrava-se em pleno florescimento e continuaram a intervalos de 10 dias uma da outra num total de 4 pulverizações. Amostras de frutos de tamanho comercial foram analisadas zero, 1, 2, 4, 6, 8 e 10 dias após a última aplicação. Imediatamente após a quarta pulverização, o resíduo médio de cipermetrina estava entre 0,25 e $0,48 \mathrm{mg} \cdot \mathrm{kg}^{-1}$ para a menor e maior dosagem, respectivamente. Estes foram reduzidos para 0,13 e 0,22 mg. $\mathrm{kg}^{-1}$, em 1 dia e 
para 0,07 e 0,08 mg. $\mathrm{kg}^{-1}$, respectivamente em 4 dias. Não foram detectados resíduos com 6 e 8 dias após a última aplicação na menor e maior dosagem, respectivamente. Com o LMR para cipermetrina estabelecido em $0,5 \mathrm{mg} \cdot \mathrm{kg}^{-1}$, até mesmo nos levantamentos iniciais os resíduos estavam abaixo dele. Para ambos os tratamentos de fenvalerate os depósitos iniciais foram de 0,29 e 0,49 $\mathrm{mg} \cdot \mathrm{kg}^{-1}$ menores que o LMR de $1 \mathrm{mg} \cdot \mathrm{kg}^{-1}$. Para deltametrina o depósito máximo inicial foi de 0,09 e $0,23 \mathrm{mg} \cdot \mathrm{kg}^{-1}$, considerados pelos autores como muito baixo.

Saldivar (1998) investigou a extensão do uso químico empregado na produção e determinou os níveis de resíduo em legumes, frutas e grãos nas principais áreas produtoras das Filipinas, no período de janeiro/1994 a junho/1996. Resíduos de alguns inseticidas, dentre estes os de deltametrina, foram encontrados em algumas amostras de tomate, maçã ampalaya (Filipinas), berinjela, pimentão e feijões de Baguio com valores tão altos que ultrapassariam a Ingestão Diária Aceitável (IDA) nas dietas, considerando-se a composição destas. Das amostras vegetais totais analisadas pelo NCPC, UPLB (National Crop Protection Center, Philippines Univ. Los Banos, College, Laguna), $51,1 \%$ continham resíduos de pesticidas e $26,82 \%$ excediam os LMRs, enquanto que $24,39 \%$ estavam abaixo. Para arroz, resíduos de deltametrina e de outros piretróides também foram encontrados. Das amostras analisadas, $56,25 \%$ continham resíduos químicos e $47,16 \%$ excediam os respectivos $L M R s$.

Prem et al. (1999) estudaram a magnitude dos resíduos de acefato, malation, endosulfan e deltametrina em frutos de tomate (cv. Roma), quando aplicados nas concentrações recomendadas, em experimentos no campo durante o verão de 1998/99 em Kullu, Himachal Pradesh (Índia). Os dados de resíduos foram agrupados para calcular parâmetros de segurança como $R L_{50}$. O depósito inicial de malation era mais alto que o de todos os outros inseticidas. Os resíduos, entretanto, apresentaram um valor de meia-vida $\left(R L_{50}\right)$ de 1,6 dia para esse inseticida, 1,8 dia para acefato, 1,6 dia para endosulfan e 1,4 dia para deltametrina. Os resíduos de acefato estavam abaixo do LMR em 3,9 dias, 
enquanto os de endosulfan 3,3 dias; e assim, um quarto dia de período de espera foi sugerido para ambos os inseticidas. Por outro lado, os depósitos iniciais de malation e deltametrina estavam abaixo do $\operatorname{LMR} e$, conseqüentemente, nenhum período de espera foi adicionalmente sugerido.

Inseticidas piretróides foram aplicados em várias culturas vegetais como tratamento foliar para determinar taxas de dissipação. Em brócolis chinês (Guy Lon), mostarda chinesa (Pak Choi) e repolho chinês (Kasumi, napa), o fenvalerate foi persistente e apresentou resíduos de 0,10, 0,14 e 0,11 mg. $\mathrm{kg}^{-1}$, respectivamente, aos 21 dias após aplicação. Resíduos de cipermetrina em alface estavam abaixo de $0,1 \mathrm{mg} \cdot \mathrm{kg}^{-1}$ aos 10 dias. Depois de três aplicações, resíduos de cipermetrina em cenouras colhidas e de permetrina em berinjela não foram encontrados no dia da aplicação. Em aspargos, os resíduos de deltametrina e cipermetrina foram menores que $0,1 \mathrm{mg}^{\mathrm{kg}}{ }^{-1}$ no $1^{\circ}$ e $2^{\circ}$ dias, respectivamente; permetrina foi mais persistente, requerendo mais que 2 dias para o resíduo ser menor $0,1 \mathrm{mg} \cdot \mathrm{kg}^{-1}$. Deltametrina não foi encontrada em cebolas (cozidas no vapor) no dia da aplicação. Em tomates, a concentração de permetrina foi de $0,093 \mathrm{mg} \cdot \mathrm{kg}^{-1}$ no dia da aplicação e diminuiu para aproximadamente $0,05 \mathrm{mg} \cdot \mathrm{kg}^{-1}$ depois de 2-4 dias. Em geral, resíduos de permetrina, cipermetrina e deltametrina estiveram dentro dos níveis e intervalo de segurança aceitáveis. Fenvalerate comportou-se como muito persistente, especialmente nestas culturas com um LMR de $0,1 \mathrm{mg} \mathrm{kg}^{-1}$ (Ripley et al., 2001).

\subsection{Carbaril}

O carbaril é um inseticida do grupo químico dos carbamatos, conhecido quimicamente como 1-naftil-N-metilcarbamato (Andrei, 1996), sua fórmula estrutural é: (Tomlin, 1995) 


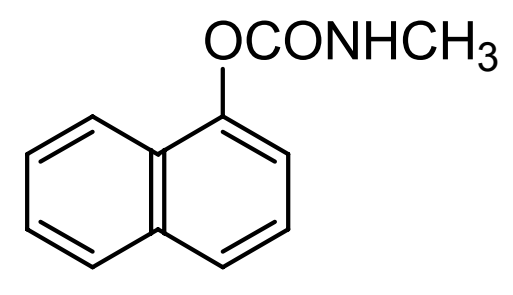

Figura 2 - Fórmula estrutural do carbaril

Tabela 2. Propriedades físicas e químicas do carbaril

\begin{tabular}{ll}
\hline \multicolumn{1}{c}{ Parâmetros } & \multicolumn{1}{c}{ Valores } \\
\hline fórmula química & $\mathrm{C}_{12} \mathrm{H}_{11} \mathrm{NO}_{2}$ \\
peso molecular & 201,2 \\
ponto de fusão & $142{ }^{\circ} \mathrm{C}$ \\
coeficiente de partição $\left(\mathrm{K}_{\mathrm{ow}}\right)$ & 1,85 \\
solubilidade em água & $120 \mathrm{mg} / \mathrm{L}\left(20{ }^{\circ} \mathrm{C}\right)$ \\
pressão de vapor $\left(23,5^{\circ} \mathrm{C}\right)$ & $4,1 \times 10^{-2} \mathrm{mPa}$ \\
\hline
\end{tabular}

Fonte: Tomlin (1995)

Possui $\mathrm{DL}_{50}$ aguda oral de 264 para ratos, 500 para fêmeas de ratos e $710 \mathrm{mg} \cdot \mathrm{kg}^{-1}$ para coelhos; $\mathrm{DL}_{50}$ aguda dérmica para ratos $>4.000$ e para coelhos > $2.000 \mathrm{mg} \cdot \mathrm{kg}^{-1}$ (Tomlin, 1995). No Brasil, é comercializado com vários nomes entre os quais: Sevin 480 SC, Sevin 850 PM, Carbaryl Fersol Pó 75, Carbaryl Fersol 480 SC e Carbaryl Fersol 850 PM, estando registrado em algumas formulações para uso em mais de 13 culturas, entre as quais a de tomate, nesta, com LMR de 0,1 mg. $\mathrm{kg}^{-1}$ (ppm) e intervalo de segurança de 3 dias (foliar) (Agência Nacional de Vigilância Sanitária, 2003b).

Os resíduos de forate granulado, aplicado no solo, e carbaril após a absorção por plantas de tomate foi estudado por Awasthi (1990). Os frutos 
tenderam a acumular teores mais altos comparado com outras partes de planta, mas os resíduos dissiparam-se rapidamente. Os de forate persistiram no solo em maiores quantidades que os de carbaril.

Frank et al (1991) estudaram, por um período de 4 anos, frutos de tomate estaqueado tratados com 11 pesticidas e colhidos com zero a 8 dias após a pulverização; tanto fruto "in natura" como suco processado foram analisados para determinação dos resíduos. Resíduos de 11 pesticidas (acefato, azinfós-metil, carbaril, demeton, diazinon, dimetoato, endosulfan, malation, permetrina, captafol e clorotalonil) estavam abaixo de $0,1 \mathrm{mg} \cdot \mathrm{kg}^{-1}$ no suco, e 8 estavam abaixo desse nível nos frutos "in natura" durante esse período. As exceções em fruto "in natura" foram clorotalonil, diazinon e azinfósmetil. Resíduos de 7 inseticidas e 2 fungicidas estavam abaixo $0,01 \mathrm{mg} \cdot \mathrm{kg}^{-1}$ no suco no período de 6 a 8 dias. Carbaril e malation foram as duas exceções. Conseqüentemente, muitos dos pesticidas requereram um intervalo de précolheita mais longo que 6-8 dias para atingir uma redução no resíduo para 0,01 $\mathrm{mg} \cdot \mathrm{kg}^{-1}$.

Monocrotofós $(0,05$ e $0,1 \%)$ e carbaril $(0,15$ e $0,3 \%)$ foram pulverizados na cultura do tomate, em três fases de desenvolvimento, especificamente, 25 dias após o transplante das mudas, $50 \%$ de florescimento e $50 \%$ formação de fruto. Os depósitos iniciais de monocrotofós nos frutos estavam entre 2,45 e 3,48 ppm para as mais baixas e altas doses, respectivamente. Os resíduos de monocrotofós 15 dias após a aplicação eram de 0,20 ppm para o tratamento a $0,05 \%$ e aos 20 dias era de 0,24 ppm nos tratamentos a $0,1 \%$. Tratamentos com $2 \%$ de extrato de tamarindo removeram 32,26 e $43,18 \%$ dos resíduos tratados com 0,05 e $0,1 \%$ de monocrotofós, respectivamente, quando o extrato foi aplicado no mesmo dia que monocrotofós. Aplicando o tratamento com o extrato 5 dias após monocrotofós resultou em uma redução de 38,45 e $29,41 \%$ dos resíduos deste inseticida para os tratamentos 0,05 e $0,1 \%$, respectivamente. Os depósitos iniciais de carbaril nos frutos foram de 7,58 e 10,32 ppm para os tratamentos a 0,15 e 0,30\%, 
respectivamente. Depois de 15 dias, os resíduos tinham dissipado a 0,6 ppm (tratamento $0,05 \%$ ) e $0,5 \mathrm{ppm}$ depois de 30 dias (tratamento $0,1 \%$ ). Os tratamentos com $2 \%$ de extrato removeram $37,95 \%$ (tratamento $0,15 \%$ ) e $36,04 \%$ (tratamento $0,30 \%$ ) quando aplicado no mesmo dia que o carbaril. Quando o extrato era aplicado 5 dias após o carbaril, os níveis de resíduos eram reduzidos a $16,53 \%(0,15 \%)$ e $39,39 \%(0,3 \%)$ (Gopichand et al., 1998).

\subsection{Descrição, Importância e Controle da broca-pequena-do-fruto}

O cultivo do tomate destinado ao consumo "in natura", ou seja, para comercialização em feiras livres, supermercados, varejões, etc, é realizado através de culturas "estaqueadas" ou "tutoradas". Já, o tomate que é destinado à indústria para processamento de polpa apresenta crescimento determinado e são rasteiros (Gravena \& De Bortoli , 1986).

A despeito do tipo de cultivo adotado, diversas pragas e doenças podem ocorrer e comprometer toda a produção se não controladas de maneira adequada. Em geral, os produtores têm muita dificuldade para tomar a decisão de controle no momento mais oportuno e, desse modo, acabam realizando pulverizações freqüentes, que, em alguns casos, ultrapassam 3 aplicações semanais.

Diversas pragas (insetos e ácaros) podem estar associadas à cultura do tomate. Entretanto, algumas delas ocorrem normalmente em altas populações e causam danos elevados à cultura. Dessa forma, tais pragas exigem atenção constante e são denominadas pragas-chave. Outras pragas podem ocorrer atacando a cultura, porém sem causar prejuízos econômicos. Estas pragas normalmente ocorrem esporadicamente e em populações baixas. Assim, tais pragas não necessitam maiores cuidados de controle. Entretanto, deve-se salientar que a ocorrência das pragas na cultura pode variar de uma região para a outra. Ainda, pragas secundárias em uma determinada região 
podem ser consideradas pragas-chave em outra. Assim, somente com a devida orientação, o produtor ou técnico pode reconhecer quais são realmente as pragas que merecem maior atenção, bem como, os níveis populacionais que causam dano econômico para garantir tomada de decisão racional (Fernandes et al., 2001).

As pragas-chave do tomateiro podem ser divididas em dois grupos: a_ brocas e traças dos frutos; e b_ insetos transmissores de doenças.

$O$ adulto da broca-pequena-do-fruto é uma mariposa que mede cerca de 25 a $30 \mathrm{~mm}$ de envergadura. Suas asas anteriores são de um branco rosado e com manchas triangulares, cor de tijolo. As posteriores são brancas e transparentes, possuindo algumas pontuações escuras, porém, suas bordas são bem brancas. Seus hábitos são noturnos, sendo a postura efetuada entre as 20 e 4 horas, junto ao cálice da flor aberta. Após a eclosão da lagarta, as larvas penetram os frutos através de orifício quase invisível, devorando a polpa e as sementes, abrindo galerias e inutilizando completamente o fruto. O período larval é de aproximadamente 20 dias. A lagarta adulta mede entre 10 e $20 \mathrm{~mm}$ de comprimento; é de cor rosada com cabeça preta. Depois de destruir os frutos dirige-se para o solo, onde transforma-se e passa a fase de pupa, da qual, após cerca de 17 dias, emerge o adulto (Biaggi, 1977).

Segundo Gallo et al. (2002), a praga é um dos grandes problemas da cultura, podendo causar prejuízos que chegam a representar $50 \%$ da produção, pois os frutos atacados ficam imprestáveis e com a polpa destruída. O controle pode ser cultural, onde se faz a catação manual dos frutos perfurados e sua posterior destruição e também a eliminação das solanáceas silvestres das proximidades da cultura do tomate; biológico: usando-se o parasitóide de ovos Trichogramma pretiosum; mas, o mais utilizado é o controle químico com produtos fosforados, carbamatos e piretróides com as pulverizações iniciadas quando os frutos estiverem pequenos, aplicando-se os inseticidas visando-se principalmente o local da postura, isto é, nas sépalas. 


\section{MATERIAL E MÉTODOS}

\subsection{Experimento}

O Experimento foi conduzido em condições de campo, no Município de Piedade-SP (coordenadas geográficas: latitude $23^{\circ} 42^{\prime} 43^{\prime \prime} \mathrm{S}$; longitude $47^{\circ} 25^{\prime} 40^{\prime \prime}$ W). O transplante das mudas foi feito no dia $08 /$ março/2003, sendo utilizada a variedade Colibri. A instalação foi realizada em 24/abril/2003, em cultura tutorada de tomate, sendo a primeira aplicação dos inseticidas realizada nesta mesma data.

O delineamento experimental utilizado foi de blocos ao acaso com 5 tratamentos e 3 repetições. $O$ isolamento entre blocos deu-se por bordaduras constituídas de duas linhas duplas de plantas, sendo as parcelas separadas dentro do bloco por 10 plantas em linhas duplas. A unidade experimental (parcela) foi constituída de 10 metros de linhas duplas espaçadas $50 \mathrm{~cm}$ entre si e, igualmente, $50 \mathrm{~cm}$ entre plantas, para plantio comercial, e 10 metros de linhas simples espaçadas $50 \mathrm{~cm}$ entre $\mathrm{si}$, e, igualmente, $50 \mathrm{~cm}$ entre plantas, para plantio experimental.

Os inseticidas utilizados foram o Sevin $480 \mathrm{SC}$ (480 g do ingrediente ativo carbaril. $\mathrm{L}^{-1}$ do produto comercial), em formulação suspensão concentrada e Decis $25 \mathrm{CE}$ ( $25 \mathrm{~g}$ do ingrediente ativo deltametrina. $\mathrm{L}^{-1}$ do produto comercial) em formulação concentrado emulsionável. Os tratamentos experimentais foram os seguintes: 


\section{Tratamentos:}

1 - nove (9) aplicações na dosagem de $40 \mathrm{~mL}$ de Decis 25 CE. $100 \mathrm{~L}^{-1}$ de água ( $1 \mathrm{~g} \mathrm{i}$. a. deltametrina.100 $\mathrm{L}^{-1}$ de água), plantio linha simples;

2 - nove (9) aplicações na dosagem de $225 \mathrm{~mL}$ de Sevin 480 SC. $100 \mathrm{~L}^{-1}(108 \mathrm{~g}$ de i. a. carbaril. $100 \mathrm{~L}^{-1}$ de água), plantio linha simples

3 - nove (9) aplicações na dosagem de $40 \mathrm{~mL}$ de Decis $25 \mathrm{CE} .100 \mathrm{~L}^{-1}$ de água ( $1 \mathrm{~g}$ i. a. deltametrina. $100 \mathrm{~L}^{-1}$ de água), plantio linha dupla;

4 - nove (9) aplicações na dosagem de $225 \mathrm{ml}$ de Sevin 480 SC. $100 \mathrm{~L}^{-1}$ (108 g de i. a. carbaril. $100 \mathrm{~L}^{-1}$ de água), plantio linha dupla;

5 - testemunha;

As aplicações foram realizadas com auxílio de um pulverizador costal mantido à pressão constante de $60 \mathrm{PSI}$ com $\mathrm{CO}_{2}$, com volume de calda de 1000 L.ha $^{-1}$, como recomendado, e suficiente para saturação da parte aérea.

A primeira aplicação ocorreu no início do período de maturação dos frutos no dia 24/abril/2003 e as demais em intervalos subseqüentes de 7 dias, num total de 9 aplicações, sendo a última realizada no dia 18/junho/2003.

Durante a realização do experimento foram tomados dados das condições climáticas, a saber: temperatura média e precipitação atmosférica no período, para correlação com os níveis de resíduos dos dois analitos (Tabela 3).

Tabela 3. Condições climáticas durante a realização do experimento,

Piedade-SP (CIIAGRO, 2003)

\begin{tabular}{cccccc}
\hline & março & abril & maio & junho & julho \\
\hline $\begin{array}{c}\text { Temperatura } \\
\text { Média }\left({ }^{\circ} \mathrm{C}\right)\end{array}$ & 22,5 & 21,0 & 18,8 & 18,3 & 17,4 \\
$\begin{array}{c}\text { Precipitação } \\
(\mathrm{mm})\end{array}$ & 53,5 & 37,0 & 11,5 & 6,4 & 4,8 \\
\hline
\end{tabular}




\subsection{Amostragens}

As amostras de frutos foram colhidas com (-1), zero, 3, 5 e 10 dias após a última aplicação, sendo a primeira amostragem em 17/junho e a última em 27/junho/2003. Elas foram constituídas de 15 frutos tomados ao acaso por parcela, 1 dia antes da última aplicação (-1), para serem analisados individualmente e assim correlacionar o nível de resíduo encontrado com o controle da broca-pequena-do-fruto, tamanho e peso dele. Nos demais dias de amostragem foram coletados 15 frutos, tomados ao acaso por parcela e desses foi preparada uma única amostra para análise de resíduos, porém, em todos, foi verificada a ocorrência ou não do dano causado pela praga. Foram colhidas 285 amostras, a saber: 15 frutos $\times 5$ tratamentos $\times 3$ repetições $\times 1$ colheita ( -1$)$ e nos demais dias: 5 tratamentos $\times 3$ repetições $\times 4$ colheitas $(0,3,5$ e 10 dias após a última aplicação).

As amostras de folhas e de solo para as análises foram tomadas com $(-1)$, zero, $1,3,10$ e 20 dias após a última aplicação, sendo a primeira amostragem em 17/junho e a última em 08/julho/2003. Foram colhidas 180 amostras, a saber: 5 tratamentos $\times 3$ repetições $\times 2$ substratos $\times 6$ colheitas. As amostras de folha foram formadas por 20 folhas compostas, tomadas ao acaso de cada parcela, buscando-se respeitar sua distribuição espacial nas plantas, de modo a torná-las tão representativas quanto possível. Para o solo, foram tomadas 6 sub-amostras ao acaso por parcela, da profundidade de $0-10 \mathrm{~cm}$, com auxílio de um trado, que formaram uma única amostra composta. 


\subsection{Limites de quantificação, porcentagens de recuperação e descrição do método de análise de resíduos de deltametrina e carbaril em amostras de fruto, folha e solo}

Para os estudos dos limites de quantificação e porcentagens de recuperação de deltametrina foram fortificadas amostras de fruto, folha e solo, de modo a se obter concentrações nos níveis: 0,01; 0,1 e 1,0 mg. $\mathrm{kg}^{-1}$ (ppm) em fruto; 0,$05 ; 0,5$ e $5,0 \mathrm{mg} \cdot \mathrm{kg}^{-1}(\mathrm{ppm})$ nas folhas e 0,$005 ; 0,05$ e $0,5 \mathrm{mg} \cdot \mathrm{kg}^{-1}(\mathrm{ppm})$ no solo. Para o inseticida carbaril foram fortificadas amostras de fruto, folha e solo, de modo a se obter concentrações nos níveis: 0,$05 ; 0,5$ e $5,0 \mathrm{mg} \cdot \mathrm{kg}^{-1}$ (ppm) em fruto; 1,$0 ; 10$ e $200 \mathrm{mg} \cdot \mathrm{kg}^{-1}$ (ppm) nas folhas e 0,$01 ; 0,1$ e 1,0 mg.kg-1 (ppm) no solo. Nos estudos, todos os níveis de fortificação, para os diversos substratos, foram feitos em triplicata. Foram fortificadas, pois, 54 amostras, a saber: 3 níveis $\times 2$ analitos $\times 3$ substratos $\times 3$ repetições.

\subsubsection{Método para análises de resíduos de deltametrina e carbaril em fruto, folha e solo}

\subsubsection{Fruto e folha}

O método de análises foi adaptado de Andersson \& Palsheden (1998), que consta da extração dos resíduos dos dois pesticidas com acetato de etila em presença de $\mathrm{Na}_{2} \mathrm{SO}_{4}$. Uma alíquota do extrato é concentrada por evaporação e os resíduos ressuspendidos em uma mistura de acetato de etila/ciclohexano; a seguir procede-se a limpeza por técnica de cromatografia de permeação em gel (GPC), sendo a eluição procedida com a citada mistura. Após nova concentração, o extrato é ressuspendido em ciclohexano/acetato de etila (1:1); segue-se determinação quantitativa realizada por técnica de cromatografia em fase gasosa, usando-se cromatógrafo HP, modelo 6890, 
provido de detector de captura de elétrons (GC/ECD) para o inseticida piretróide (deltametrina) e cromatógrafo HP, modelo 6890 Plus, equipado com detector seletivo de massas (GC/MSD) para o inseticida carbamato (carbaril).

\section{A. Aparelhos/Equipamentos}

- cromatógrafo de gás, HP, modelo 6890, equipado com detector de captura de elétrons $\left(\mu-\mathrm{ECD}, \mathrm{Ni}^{63}\right.$ ) (deltametrina);

- cromatógrafo de gás HP, modelo 6890 Plus, provido de detector seletivo de massas (carbaril);

- software ChemStation, Rev. A.06.03 (509) (deltametrina);

- software ChemStation, G1701BA, versão B.01.00 (GC/MS) (carbaril);

- coluna cromatográfica, megabore, HP-608, 30 m comprimento, diâmetro $0,53 \mathrm{~mm}$ e $0,5 \mu \mathrm{m}$ espessura do filme (deltametrina);

- coluna cromatográfica, HP-05 MS, 30 m comprimento, diâmetro 0,25 mm e $0,25 \mu \mathrm{m}$ de espessura do filme (carbaril);

- triturador Ultra-turrax, Heidolph, modelo DIA.900;

- evaporador TurboVap LV, Zymark, modelo LV;

- colunas (duas, ligadas em série) PLGel, para cromatografia de permeação em gel, 300 x 7,5 mm $\phi$;

- bomba binária, Gilson, modelo 321 ;

- injetor/coletor de frações, Gilson, modelo 215, para cromatografia de permeação em gel;

- agitador/homogeneizador, Minishaker, modelo MS-1;

- multiprocessador Sire Cutter;

- centrífuga, Revan, modelo Ciclo C-I;

- balança analítica, Mettler, modelo H10;

- balança analítica, Sartorius, modelo Basic; 
- pipetador de graduação regulável, Pipetman, Gilson P 10 mL;

- ultra-som, Mini-som.

\section{B. Solventes/Reagentes}

- acetona, PA-ACS, destilada em destilador de vidro;

- acetato de etila, nanograde, Mallinckrodt;

- ciclohexano, PA-ACS, destilado em destilador de vidro;

- éter etílico, nanograde, Mallickrodt;

- hexano, nanograde, Mallinckrodt;

- $\mathrm{Na}_{2} \mathrm{SO}_{4}$, anidro granulado, QM;

- dodecano;

- $\quad$ sílica-gel, dessecante azul;

- padrão analítico de deltametrina;

- padrão analítico de carbaril;

\section{Vidrarias e outros materiais}

- $\quad$ micro-seringa, $10 \mu \mathrm{l}$, Hamilton;

- frascos de vidro com tampa rosqueável de $200 \mathrm{~mL}$, Duran-Schott;

- manifold, 6 bicos;

- $\quad$ provetas graduadas, 25,50 e $100 \mathrm{~mL}$;

- $\quad$ pipetas graduadas, 1,5 e $10 \mathrm{~mL}$;

- $\quad$ pipetador automático, Handy Step - Brand;

- erlenmayers, 250 mL, Corning/Pyrex 5020;

- beakers, $150 \mathrm{~mL}$, Corning/Pyrex 1000;

- tubos de centrífuga, graduado, $15 \mathrm{~mL}$, Corning/Pyrex 8080; 
- $\quad$ seringas hipodérmicas, $B-D$, plástico, $5 \mathrm{~mL}$ e $10 \mathrm{~mL}$;

- filtros de membrana, Millipore 0,20 $\mu$ (Millex FG);

- $\quad$ tubos de centrífuga, polipropileno, $50 \mathrm{~mL}$, Corning 25330-50;

- vials, vidro, 1,5 mL, próprios para uso no injetor automático;

- filtro de sílica-gel;

- pipetas de Pasteur;

- $\quad$ suportes de para tubos de centrífuga;

- tubos de ensaio de $12 \mathrm{~mL}$;

\section{Preparação das soluções padrão}

Inicialmente são preparadas soluções estoque de deltametrina e de carbaril em acetona. Para tanto, os padrões analíticos dos pesticidas são solubilizados no citado solvente, de modo a fornecer concentração exata de 1 $\mathrm{mg} \cdot \mathrm{mL}^{-1}$ (soluções estoque). As soluções padrão para estudos de fortificações e injeções nos sistemas cromatográficos GC/ECD (deltametrina) e GC/MSD (carbaril), são preparadas a partir das soluções estoque com diluições feitas, igualmente em acetona.

\section{E. Fortificações}

Para os estudos de fortificação/recuperação, as amostras (frutos, folhas) foram fortificadas juntando-se $1 \mathrm{~mL}$ das soluções de concentrações apropriadas, obtidas por diluições sucessivas, a partir das soluções estoque, em sub-amostras de $10 \mathrm{~g}$ cada uma dos substratos obtidos de frutos ou folhas triturados/homogeneizados, sabidamente nunca anteriormente contaminados. 


\section{F. Extração}

F.01. Pesar $10 \mathrm{~g}$ da amostra homogeneizada, adequadamente fortificada, colocar um tubo Duran-Schott, juntar $50 \mathrm{~mL}$ de acetato de etila, $10 \mathrm{~g}$ de $\mathrm{Na}_{2} \mathrm{SO}_{4}$ e triturar no aparelho Ultra-turrax durante 2 minutos a $26.000 \mathrm{rpm}$.

F.02. Centrifugar a $2.500 \mathrm{rpm}$ por 5 minutos para melhor separar a fase líquida do material em suspensão.

F.03.01. (deltametrina - fruto) Transferir alíquota de $5 \mathrm{~mL}$ do sobrenadante em tubos de ensaio de $12 \mathrm{~mL}$.

F.03.02. (carbaril - fruto) Transferir alíquota de $10 \mathrm{~mL}$ do sobrenadante e adicionar $50 \mu \mathrm{L}$ de dodecano em tubos de ensaio de $12 \mathrm{~mL}$.

F.03.03 (deltametrina - folha) Transferir alíquota de $5 \mathrm{~mL}$ do sobrenadante em tubos de ensaio de $12 \mathrm{~mL}$.

F.03.04. (carbaril - folha) Transferir alíquota de $5 \mathrm{~mL}$ do sobrenadante e adicionar $50 \mu \mathrm{L}$ de dodecano em tubos de ensaio de $12 \mathrm{~mL}$.

F.04. Evaporar em Turbo Vap-LV, a $40^{\circ} \mathrm{C}$, com auxílio de ar movente, previamente seco em filtro de sílica-gel dessecante azul, até secar.

\section{G. Limpeza}

G.01.01. (deltametrina - fruto e folha) Preparar coluna cromatográfica montada em seringa hipodérmica de $10 \mathrm{~mL}$, com $2 \mathrm{~g}$ de $\mathrm{SiOH}$ (sílica gel) e 0,5 g de sulfato de sódio anidro; condicionar com $10 \mathrm{~mL}$ de hexano, lavar o tubo de ensaio com $3 \times 5 \mathrm{~mL}$ de hexano (homogeneizar em agitador Minishaker e ultra-som), lavar a coluna com $3 \mathrm{~mL}$ de hexano/éter etílico (9:1) e descartar os eluatos; lavar a coluna com mais $2 \times 6 \mathrm{~mL}$ de hexano/éter (9:1) e coletar os eluatos; 
G.01.02. (carbaril - fruto) Ressuspender os resíduos provenientes de F.03.02.em $2 \mathrm{~mL}$ da mistura de acetato de etila/ciclohexano $(1 / 1, \mathrm{v} / \mathrm{v})$, lavando muito bem as paredes internas do tubo de ensaio.

G.01.01.01. (deltametrina - fruto) Evaporar totalmente o solvente em Turbo Vap - LV e ressuspender com $4 \mathrm{~mL}$ de ciclohexano/acetato de etila (1:1).

G.01.01.02. (deltametrina - folha) Evaporar totalmente o solvente em Turbo Vap - LV e ressuspender com $10 \mathrm{~mL}$ de ciclohexano/acetato de etila (1:1).

G.01.03. (carbaril - folha) Ressuspender os resíduos provenientes de F.03.04. em $10 \mathrm{~mL}$ da mistura ciclohexano/acetato de etila (1:1)

G.02. Agitar em aparelho agitador/homogenizador Minishaker por cerca de 1 minuto, e deixar em ultra-som também por cerca de 1 minuto.

G.03. Filtrar o extrato em filtro de membrana Millipore de malha de $0,20 \mu \mathrm{m}$, com auxílio de uma seringa hipodérmica de $5 \mathrm{~mL}$, transferindo o extrato para frascos próprios de uso no GPC;

G.04. Injetar o extrato no aparelho GPC e operar o equipamento com fase móvel da mesma mistura de acetato de etila/ciclohexano (1:1), com fluxo de $1 \mathrm{~mL} \cdot \mathrm{min}^{-1}$, descartando os eluatos durante os primeiros 14 minutos e coletando a fração em eluição nos 2 minutos subseqüentes (deltametrina) e descartando os eluatos durante os primeiros 17 minutos e coletando a fração em eluição nos 2 minutos subseqüentes (carbaril), em um tubo de ensaio de $12 \mathrm{~mL}$. Adicionar $50 \mu \mathrm{L}$ de dodecano somente nos extratos de carbaril.

G.05. Evaporar os extratos contidos nos tubos de ensaio em TurboVap LV sob leve corrente de $\mathrm{N}_{2}$ a $40^{\circ} \mathrm{C}$, até secar; nos extratos de carbaril adicionar 50 $\mu \mathrm{L}$ de dodecano. 


\section{H. Determinação quantitativa}

H.01.01 .(deltametrina - fruto e folha) Ressuspender os resíduos provenientes de G.05. em $1 \mathrm{~mL}$ de ciclohexano/acetato de etila (1:1).

H.01.02. (carbaril - fruto) Ressuspender os resíduos provenientes de G.05. em $0,45 \mathrm{~mL}$ de ciclohexano/acetato de etila (1:1).

H.01.03. (carbaril - folha) Ressuspender os resíduos provenientes de G.05. em $0,95 \mathrm{~mL}$ de ciclohexano/acetato de etila (1:1).

H.02. Transferir os extratos para frascos próprios de uso nos injetores automáticos dos cromatógrafos, com auxílio de pipetas de Pasteur.

H.03. Injetar alíquotas nos cromatógrafos, com operação em programação de temperaturas.

H.04. Condições de operação dos cromatógrafos:

H.04.02. Deltametrina (GC/ECD)

Temperaturas:

injetor: $250^{\circ} \mathrm{C}$

coluna: $100^{\circ} \mathrm{C}$, mantém 1 minuto,

$280^{\circ} \mathrm{C}$, @ 23,5 $\mathrm{C} / \mathrm{min}$, mantém 12 minutos, detector: $320^{\circ} \mathrm{C}$

Fluxos dos gases:

$$
\begin{aligned}
& \mathrm{H}_{2} \text { (arraste) }=6,0 \mathrm{~mL} \cdot \mathrm{min}^{-1} ; \\
& \mathrm{N}_{2} \text { (make up) }=30 \mathrm{~mL} \cdot \mathrm{min}^{-1} .
\end{aligned}
$$

Tempos de retenção: deltametrina 14 minutos

H.04.01. Carbaril (GC/MSD)

Temperaturas:

injetor: $230^{\circ} \mathrm{C}$

coluna: $100^{\circ} \mathrm{C}$, mantém 1 minuto,

$280^{\circ} \mathrm{C} @ 20^{\circ} \mathrm{C} / \mathrm{min}$., mantém 3 minutos; 
detector: seletivo de massas

Fluxos dos gases:

He: $1 \mathrm{~mL} \cdot \mathrm{min}^{-1}$.

Fluxo de purga: $24 \mathrm{~mL} / \mathrm{min}$

Tempo de purga:1,0 min

Monitoramento de íons (SIM)

Fragmento de quantificação: 115

Fragmento de confirmação: 144

Tempos de retenção:

carbaril 9 minutos

\section{Cálculo das porcentagens de recuperação e dos resíduos}

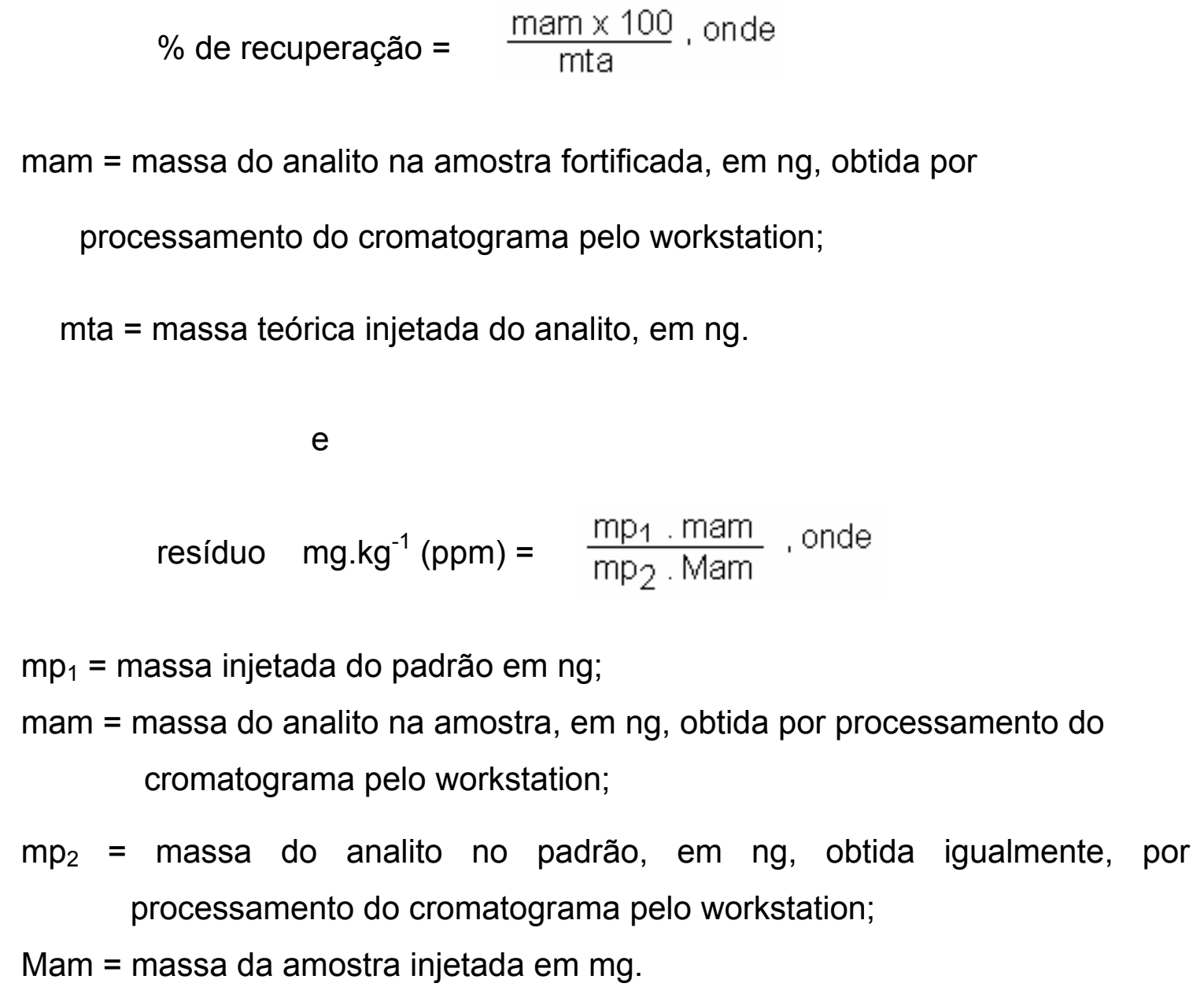




\subsubsection{Solo}

Os estudos de fortificação/recuperação com amostras de solo tiveram sua preparação, determinação quantitativa e cálculo das porcentagens de recuperação e resíduos em tudo muito semelhantes aos procedimentos descritos para frutos e folhas, diferindo, entretanto, quanto às operações de extração dos resíduos dos dois pesticidas, às quais foram executadas em extrator acelerado de solvente (marca Dionex, modelo ASE 300). Assim, as operações quanto à extração dos resíduos podem ser assim descritas:

\section{F. Extração}

F.01. Pesar $20 \mathrm{~g}$ de solo (seco ao ar) adequadamente fortificada, colocar na célula de extração do aparelho ASE 300 , juntar $\mathrm{Na}_{2} \mathrm{SO}_{4}$ suficiente para completar o volume da célula.

F.02. Extrair em ASE 300, usando-se acetato de etila, operando o aparelho a $100^{\circ} \mathrm{C}$ e pressão positiva de $1.500 \mathrm{psi}$, por cerca de 15 minutos, obtendose os extratos (cerca de $120 \mathrm{~mL}$ ) coletados nos frascos de uso próprio do aparelho.

F.03. Transferir os extratos para tubo de Turbo-Vap II, passando por funil contendo cerca de $30 \mathrm{~g}$ de $\mathrm{Na}_{2} \mathrm{SO}_{4}$; lavar funil com $20 \mathrm{~mL}$ de acetato de etila, recolhendo esta fração no mesmo tubo;

F.04. Evaporar até $1 \mathrm{~mL}$ em TurboVap II (evaporador Zymark, modelo TurboVap II), sob leve fluxo de $\mathrm{N}_{2}$ a $40^{\circ} \mathrm{C}$ até secar. Lavar as paredes do tubo com acetato de etila e concentrar novamente até $1 \mathrm{~mL}$, adicionar mais $1 \mathrm{~mL}$ de acetato de etila e $2 \mathrm{~mL}$ de ciclohexano.

F.05. Homogeneizar em agitador Minishaker (15 seg) e ultra-som (1 min.) 


\section{G. Limpeza}

G.01. Filtrar o extrato em filtro de membrana Millipore de malha de $0,20 \mu \mathrm{m}$, com auxílio de uma seringa hipodérmica de $5 \mathrm{~mL}$, transferindo o extrato para vials próprios de uso no GPC; Continuar como em G.04. de fruto e folha.

\section{H. Determinação quantitativa}

H.01.01. (deltametrina) Evaporar o solvente em Turbo-Vap a $40^{\circ} \mathrm{C}$. Ressuspender em $2 \mathrm{~mL}$ de ciclohexano/acetato de etila (1:1).

H.01.02. (carbaril) Adicionar $50 \mu \mathrm{L}$ de dodecano e evaporar o solvente em Turbo-Vap - LV a $40{ }^{\circ} \mathrm{C}$. Ressuspender em $0,95 \mathrm{~mL}$ de ciclohexano/acetato de etila (1:1).

H.02. Prosseguir como em H.02., do método descrito para frutos e folhas, até o final.

\subsection{Avaliação da infestação da broca-pequena-do-fruto}

Para a avaliação da ocorrência da praga e eficiência dos tratamentos com inseticidas, os 15 frutos amostrados por parcela para a análise de resíduos, foram cortados, e assim foi verificada a presença ou não de danos causados pela broca. Esses dados foram anotados e transformados para serem expressos em porcentagem de frutos atacados. 


\section{RESULTADOS E DISCUSSÃO}

\subsection{Limites de quantificação e porcentagens de recuperação dos métodos}

de análises de resíduos de deltametrina e carbaril em amostras de fruto, folha e solo

Os resultados obtidos nos estudos de fortificação/recuperação de deltametrina e carbaril em amostras de frutos, folhas e solo são apresentados nas Tabelas 4 a 6.

Tabela 4. Porcentagens (\%) de recuperação de resíduos de deltametrina e de carbaril em amostras fortificadas de frutos de tomate

\begin{tabular}{ccc}
\hline Níveis de fortificação & \multicolumn{2}{c}{ Recuperação (\%) } \\
(média de 3 repetições) \\
$\left(\mathrm{mg} \cdot \mathrm{kg}^{-1}\right)(\mathrm{ppm})$ & deltametrina & carbaril \\
\hline 0,01 & $108 \pm 7 \%$ & - \\
0,10 & $98 \pm 7 \%$ & - \\
1,00 & $92 \pm 7 \%$ & - \\
0,05 & - & $102 \pm 4 \%$ \\
0,50 & - & $92 \pm 5 \%$ \\
5,00 & - & $89 \pm 5 \%$ \\
\hline
\end{tabular}


Tabela 5. Porcentagens (\%) de recuperação de resíduos de deltametrina e de carbaril em amostras fortificadas de folhas de tomate

\begin{tabular}{|c|c|c|}
\hline \multirow[t]{2}{*}{ Níveis de fortificação } & \multicolumn{2}{|c|}{ Recuperação (\%) } \\
\hline & \multicolumn{2}{|c|}{ (média de 3 repetições) } \\
\hline$\left(m g \cdot \mathrm{kg}^{-1}\right)(\mathrm{ppm})$ & deltametrina & carbaril \\
\hline 0,05 & $110 \pm 8 \%$ & - \\
\hline 0,50 & $101 \pm 7 \%$ & - \\
\hline 5,00 & $93 \pm 5 \%$ & - \\
\hline 1,00 & - & $89 \pm 5 \%$ \\
\hline 10,0 & - & $84 \pm 4 \%$ \\
\hline 200 & - & $74 \pm 3 \%$ \\
\hline
\end{tabular}

Tabela 6. Porcentagens (\%) de recuperação de resíduos de deltametrina e de carbaril em amostras fortificadas de solo

\begin{tabular}{ccc}
\hline Níveis de fortificação & \multicolumn{2}{c}{$\begin{array}{c}\text { Recuperação (\%) } \\
\text { (média de 3 repetições) }\end{array}$} \\
$\left(\mathrm{mg}^{\mathrm{kg}} \mathrm{-}^{-1}\right)(\mathrm{ppm})$ & deltametrina & carbaril \\
\hline 0,005 & $112 \pm 9 \%$ & - \\
0,050 & $99 \pm 8 \%$ & - \\
0,500 & $98 \pm 3 \%$ & - \\
0,010 & - & $97 \pm 3 \%$ \\
0,100 & - & $88 \pm 7 \%$ \\
1,000 & - & $90 \pm 7 \%$ \\
\hline
\end{tabular}

Nas condições experimentais, o método analítico mostra-se satisfatório para as análises de resíduos dos dois pesticidas, com limites de 
quantificação (LOQ) de $0,01 \mathrm{mg} \cdot \mathrm{kg}^{-1} \mathrm{em}$ frutos, $0,05 \mathrm{mg} \cdot \mathrm{kg}^{-1} \mathrm{em}$ folha e em solo ao nível de $0,005 \mathrm{mg} \cdot \mathrm{kg}^{-1}(\mathrm{ppm})$ para deltametrina e $0,05 \mathrm{mg} \cdot \mathrm{kg}^{-1} \mathrm{em}$ frutos, 1,0 $\mathrm{mg} \cdot \mathrm{kg}^{-1} \mathrm{em}$ folhas e de $0,01 \mathrm{mg} \cdot \mathrm{kg}^{-1}$ (ppm) em solo para carbaril. Abaixo destes níveis, os materiais interferentes, eluídos nos cromatogramas, prejudicam consideravelmente a resolução destes. Desse modo, o método para análises multi-resíduos de Andersson \& Palshelden (1998), descrito para frutas e verduras (inclusive para tomate para análises dos dois analitos), confirma sua aplicabilidade, bem como mostra-se, também, exeqüível para amostras folhas e de solo e para os dois analitos.

\subsection{Experimento}

Os resultados obtidos no experimento são apresentados nas Tabelas de 7 a 15. Cromatogramas típicos das análises são apresentados nas Figuras de 4 a 10 .

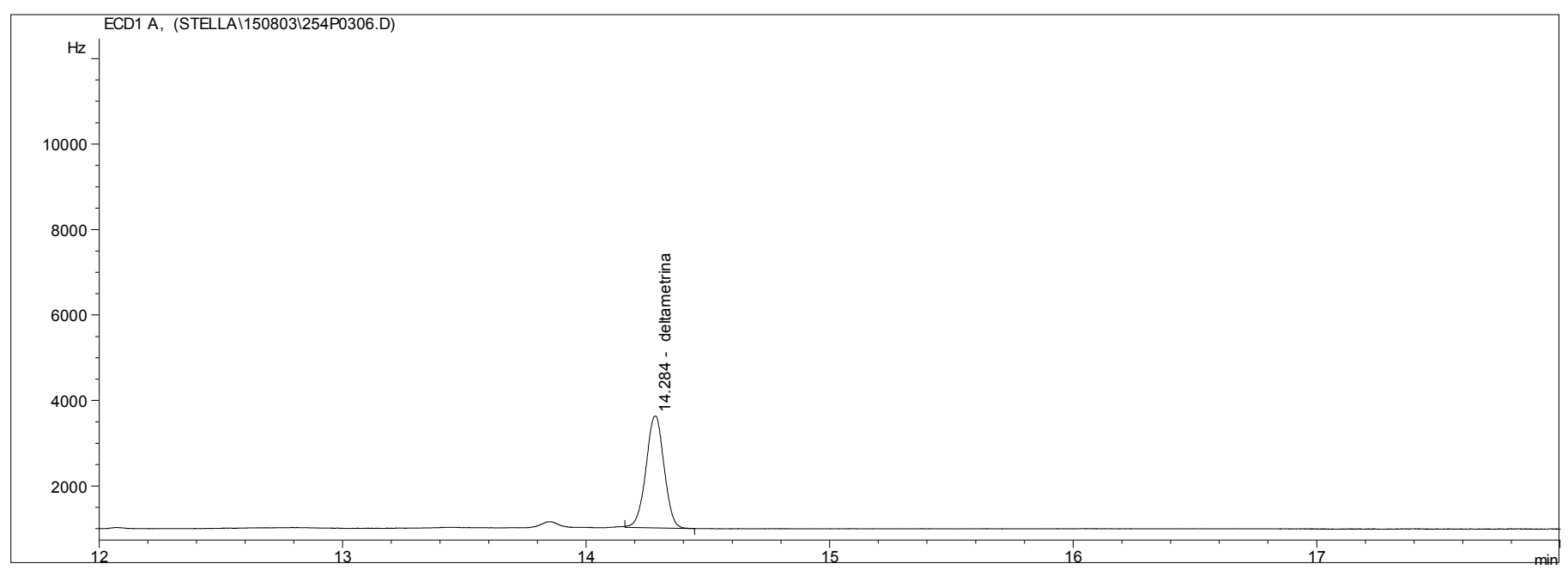

Figura 3 - Cromatograma de padrão de deltametrina $50 \mathrm{pg}-2 \mu \mathrm{L}-100 \mathrm{pg}$ 


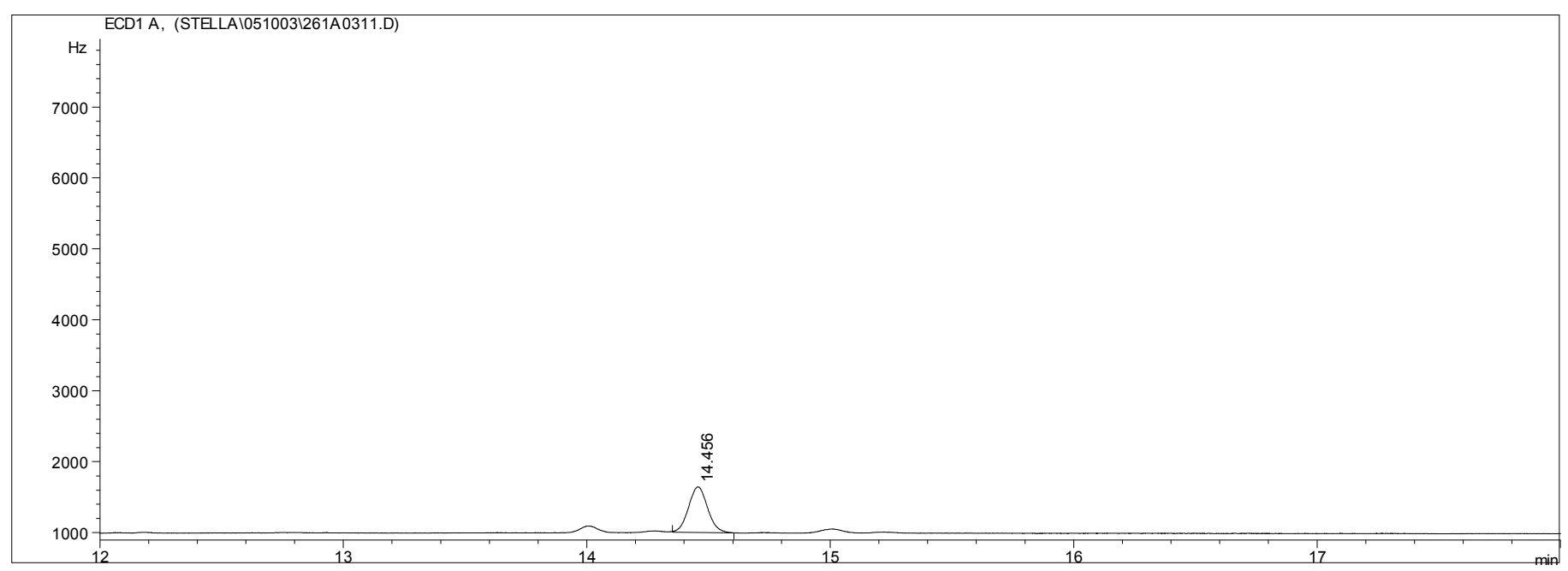

Figura 4 - Cromatograma de amostra de fruto (deltametrina), tratamento linha simples $-2 \mu \mathrm{L}-0,25 \mathrm{mg}$

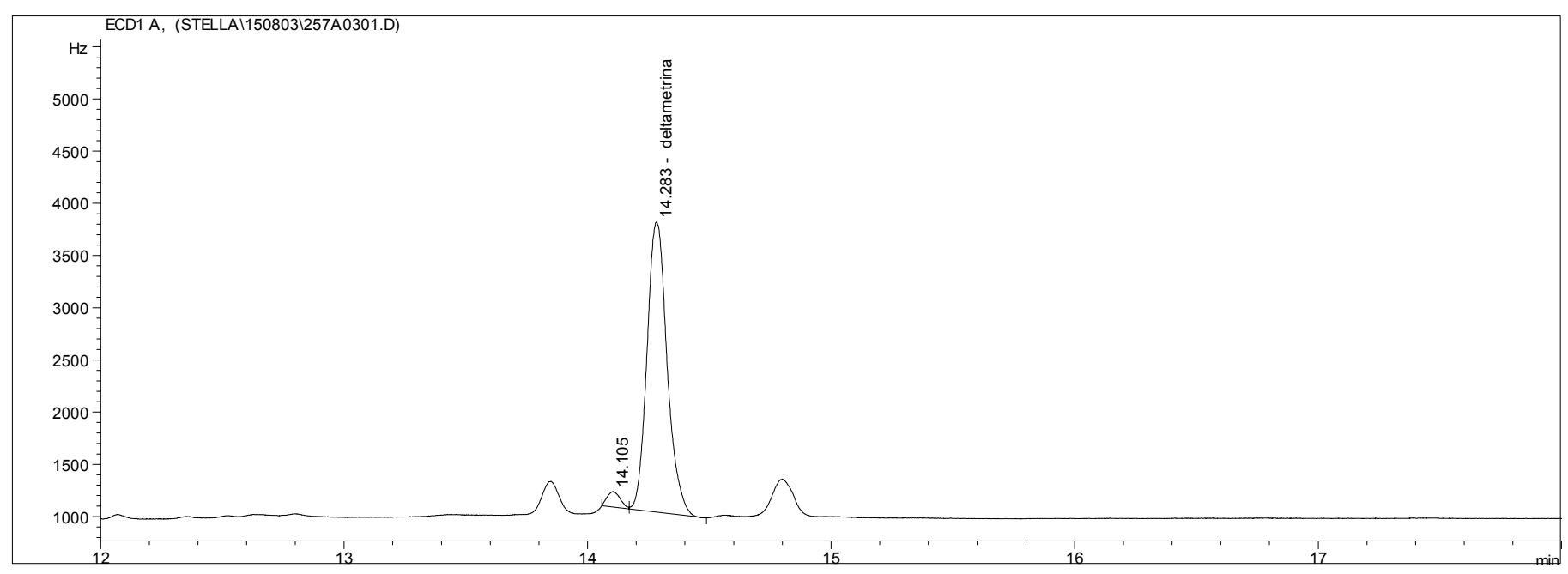

Figura 5 - Cromatograma de amostra de folha (deltametrina) tratamento linha simples $-2 \mu \mathrm{L}-0,1 \mathrm{mg}$ 


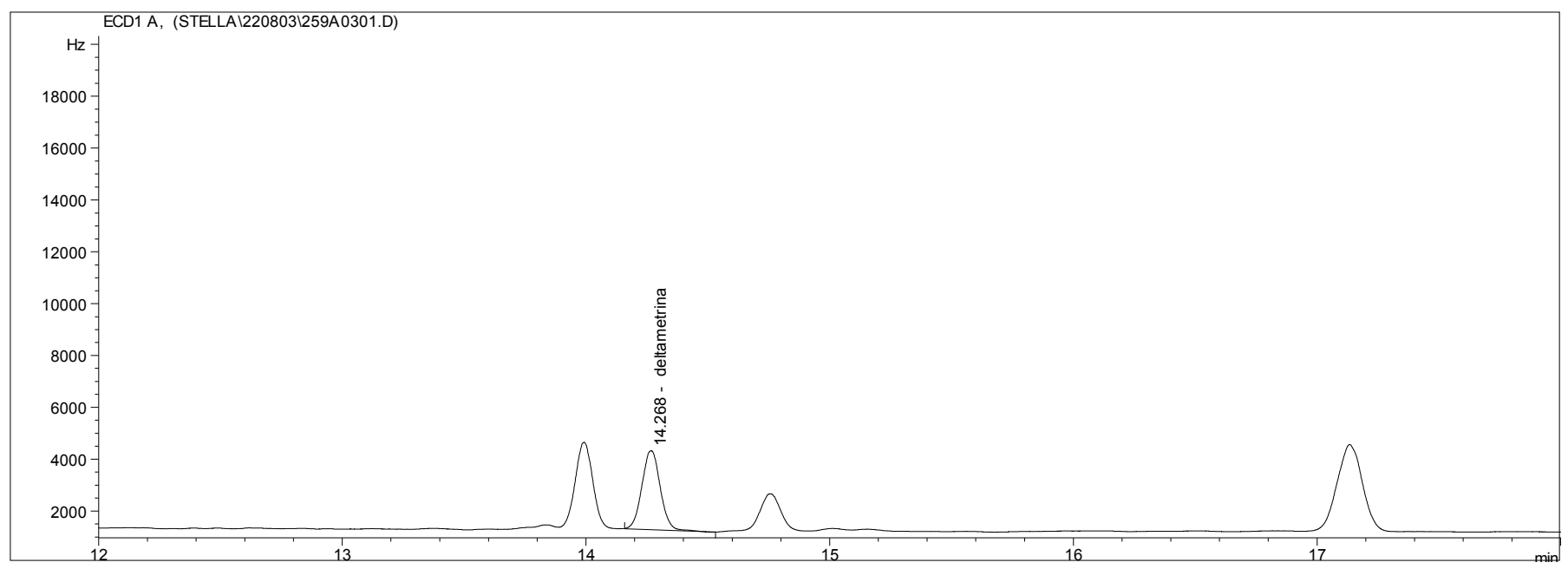

Figura 6 - Cromatograma de amostra de solo (deltametrina) tratamento linha simples $-2 \mu \mathrm{L}-2,5 \mathrm{mg}$

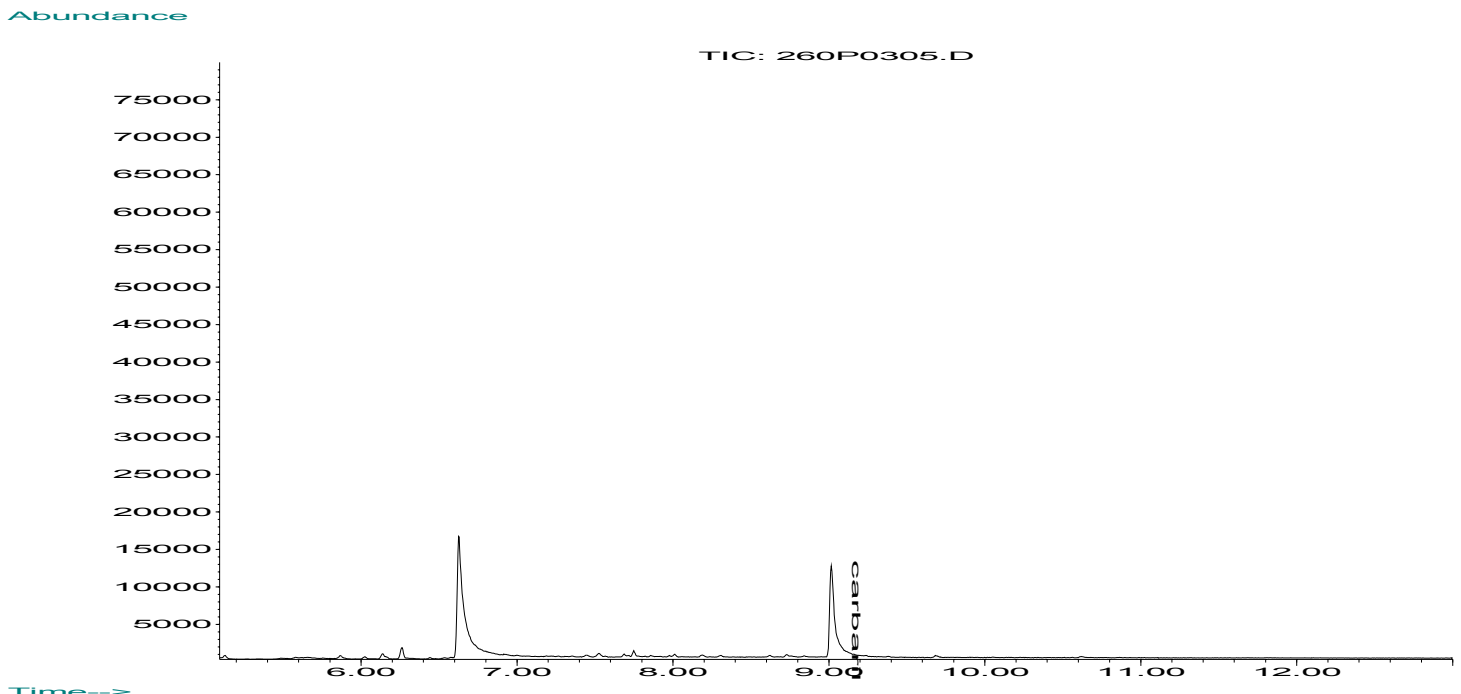

Figura 7 - Cromatograma de padrão (carbaril) - 200 pg $-2 \mu \mathrm{L}-400$ pg 


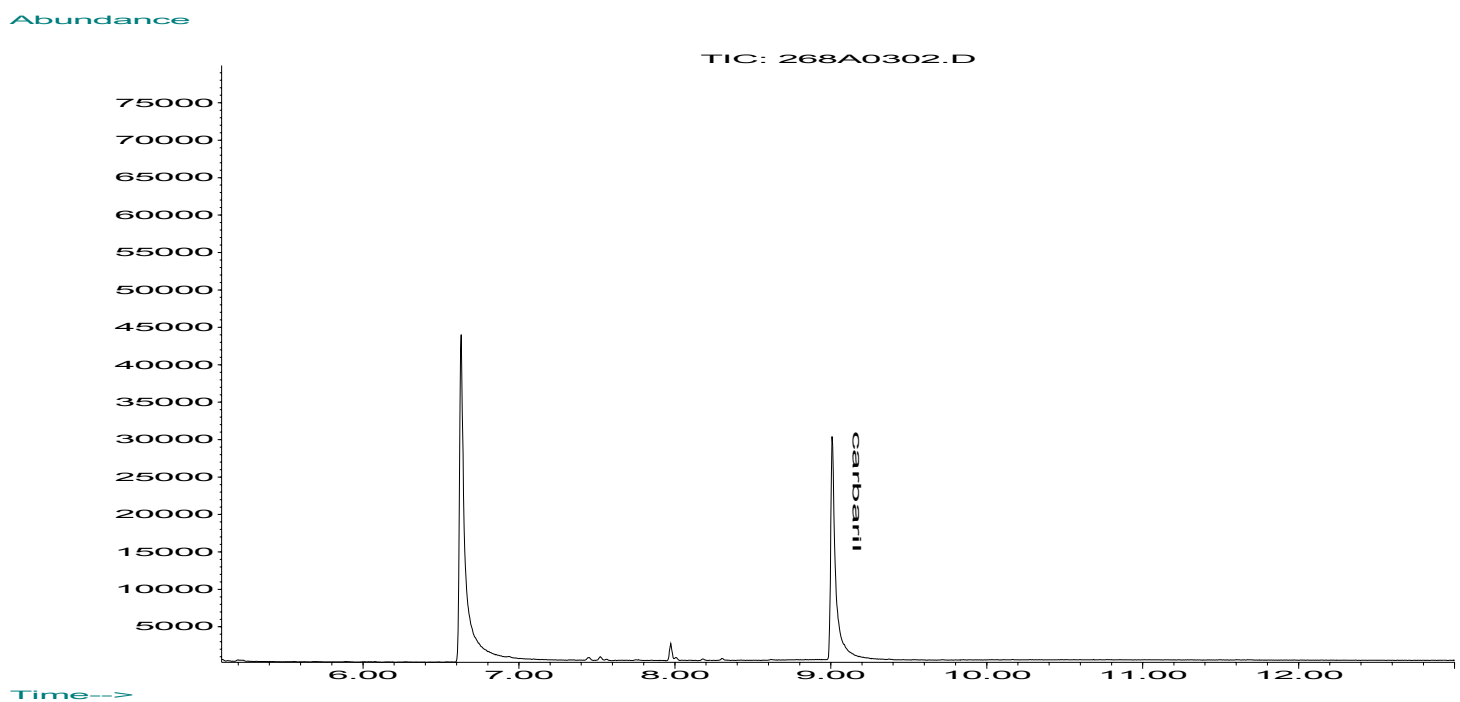

Figura 8 - Cromatograma de amostra de fruto (carbaril) tratamento linha simples

$-2 \mu \mathrm{L}-2 \mathrm{mg}$

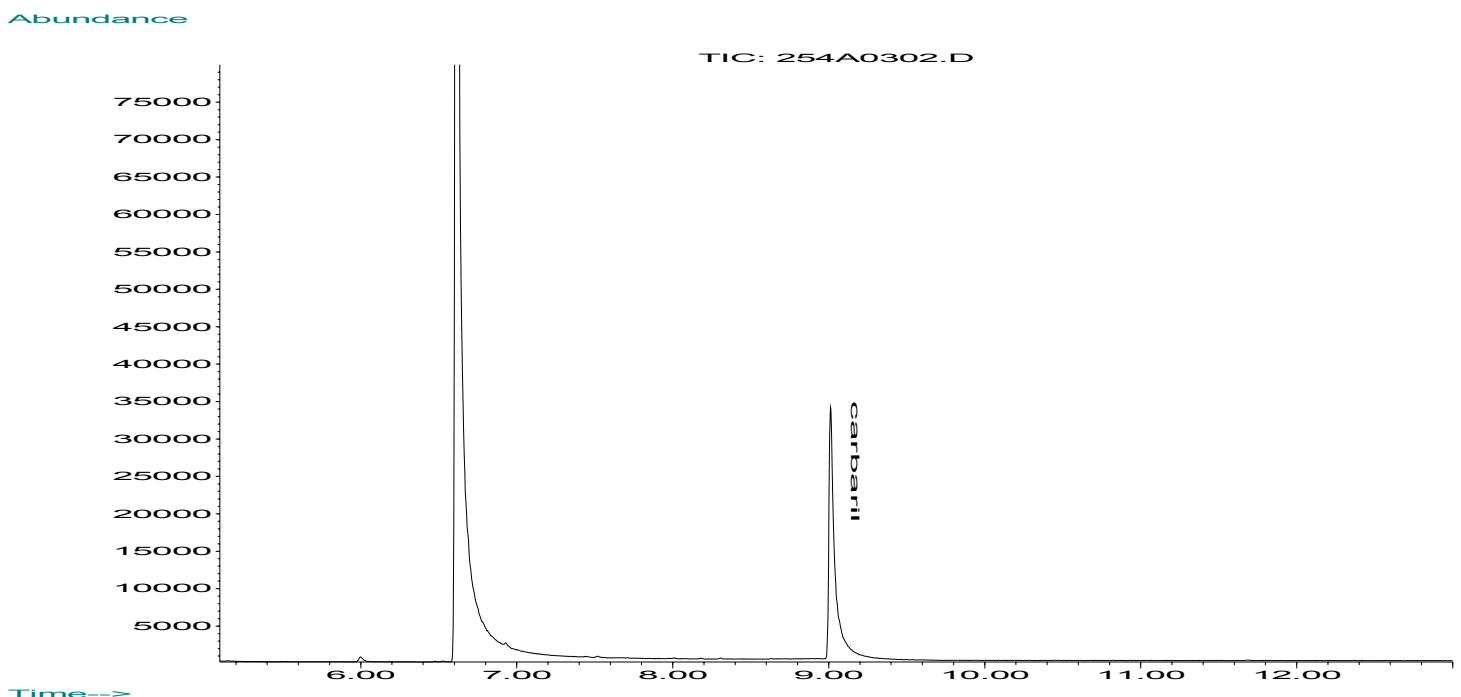

Figura 9 - Cromatograma de amostra de folha (carbaril) tratamento linha simples $-2 \mu \mathrm{L}-0,1 \mathrm{mg}$ 


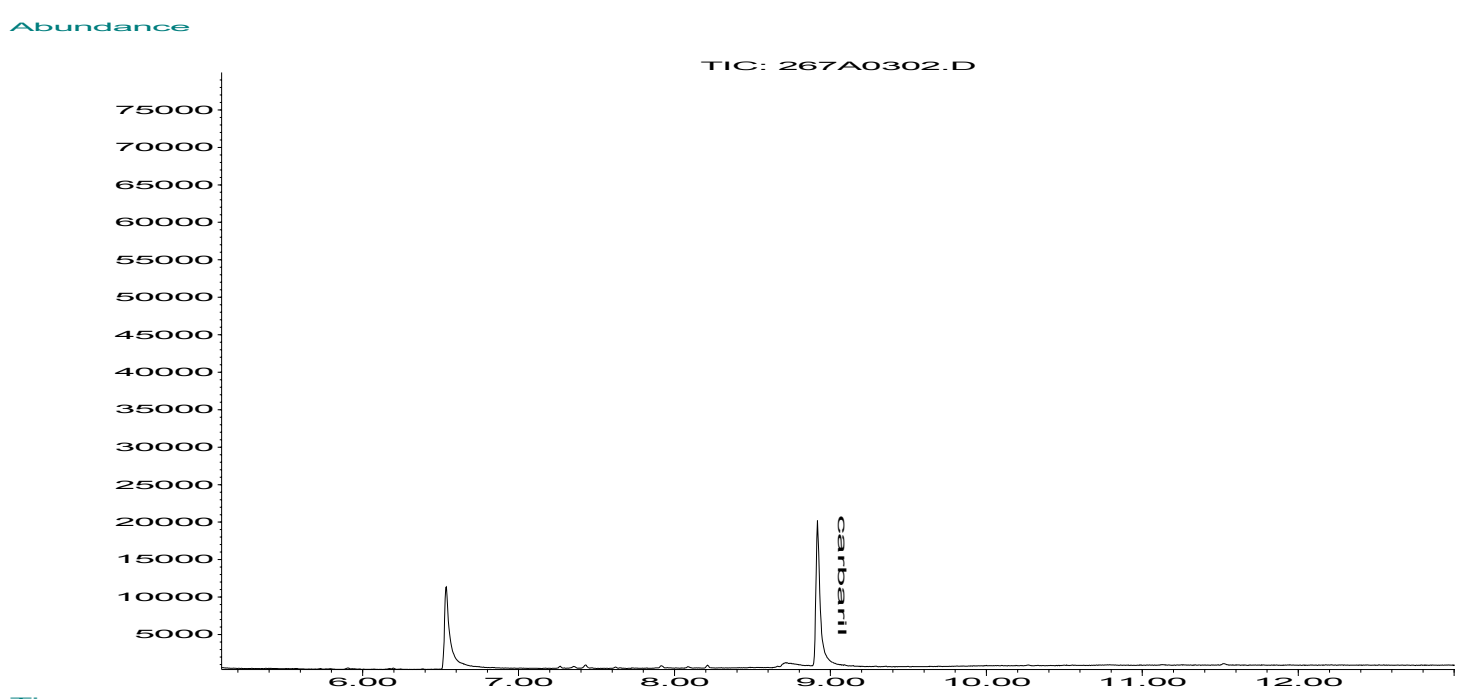

Figura 10 - Cromatograma de amostra de solo (carbaril) tratamento linha simples $-2 \mu \mathrm{L}-5 \mathrm{mg}$

Tabela 7. Média de resíduos dos inseticidas, peso, altura, diâmetro e número de frutos brocados colhidos um dia antes da última aplicação

\begin{tabular}{|c|c|c|c|c|c|}
\hline Tratamento & $\begin{array}{l}\text { Resíduo } \\
\left(\mathrm{mg} \cdot \mathrm{kg}^{-1}\right)\end{array}$ & $\begin{array}{l}\text { Peso } \\
(\mathrm{g})\end{array}$ & $\begin{array}{l}\text { Altura } \\
(\mathrm{mm})\end{array}$ & $\begin{array}{c}\text { Diâmetro } \\
\text { (mm) }\end{array}$ & $\begin{array}{l}\text { Número de } \\
\text { frutos } \\
\text { brocados }\end{array}$ \\
\hline $\begin{array}{l}\text { 1-deltametrina/ } \\
\text { linha simples }\end{array}$ & $0,015 b$ & $157,06 a$ & $87,76 a$ & $60,78^{a}$ & $0,11 a$ \\
\hline $\begin{array}{c}\text { 2-carbaril/ } \\
\text { linha simples }\end{array}$ & $0,127 a$ & $132,28 a$ & $82,58 a$ & $56,87^{\mathrm{a}}$ & $0,04 a$ \\
\hline $\begin{array}{l}\text { 3-deltametrina/ } \\
\text { linha dupla }\end{array}$ & $0,010 b$ & $150,26 a$ & $82,60 a$ & $59,96 a$ & $0,20 a$ \\
\hline $\begin{array}{l}\text { 4-carbaril/ } \\
\text { linha dupla }\end{array}$ & 0,070ab & $164,91 \mathrm{a}$ & $87,83 a$ & $61,54 a$ & $0,13 a$ \\
\hline 5-Testemunha & $0,000 b$ & $143,16 a$ & $84,49 a$ & $58,40 a$ & $0,24 a$ \\
\hline
\end{tabular}


As médias dos parâmetros: resíduo, peso, altura, diâmetro e número de frutos brocados foram comparados pelo teste de Tukey $(P \leq 0,05)$ (SANEST, 2003). Verificou-se que não houve diferença significativa entre médias de tratamentos para os parâmetros: resíduo, peso, altura, diâmetro e número de frutos. Somente para resíduo, observou-se a superioridade estatística do tratamento 2 em relação aos 1, 3 e 5 , embora não tenha diferido do tratamento 4 (Tabela 7).

Tabela 8. Correlação (Pearson) e respectivas probabilidades (Bonferroni) entre os parâmetros: resíduo, peso, altura, diâmetro e número de frutos brocados

\begin{tabular}{cccccc}
\hline Resíduo & Peso $(\mathrm{g})$ & Altura $(\mathrm{mm})$ & $\begin{array}{c}\text { Diâmetro } \\
(\mathrm{mm})\end{array}$ & $\begin{array}{c}\text { Número de } \\
\text { frutos } \\
\text { brocados }\end{array}$ \\
\hline Resíduo & 1.000 & & & & \\
Peso & -0.272 & 1.000 & & & \\
& $(1.000)$ & & & & \\
Altura & -0.179 & 0.868 & 1.000 & & \\
& $(1.000)$ & $(0.000)$ & & & \\
Diâmetro & -0.249 & 0.938 & 0.754 & 1.000 & \\
& $(1.000)$ & $(0.000)$ & $(0.012)$ & & \\
Número de & -0.535 & 0.1491 & 0.097 & 0.121 & \\
frutos & $(0.400)$ & $(1.000)$ & $(1.000)$ & $(1.000)$ & \\
brocados & & & & & \\
\hline
\end{tabular}

Pela tabela 8 verifica-se a concentração $\left(\mathrm{mg} \cdot \mathrm{kg}^{-1}\right)$ de resíduo encontrado nos frutos não apresenta correlação com os parâmetros peso, altura, diâmetro e número de frutos brocados. As correlações significativas encontradas foram entre peso e diâmetro, peso e altura e, altura e diâmetro $(P \leq 0,02)$. 


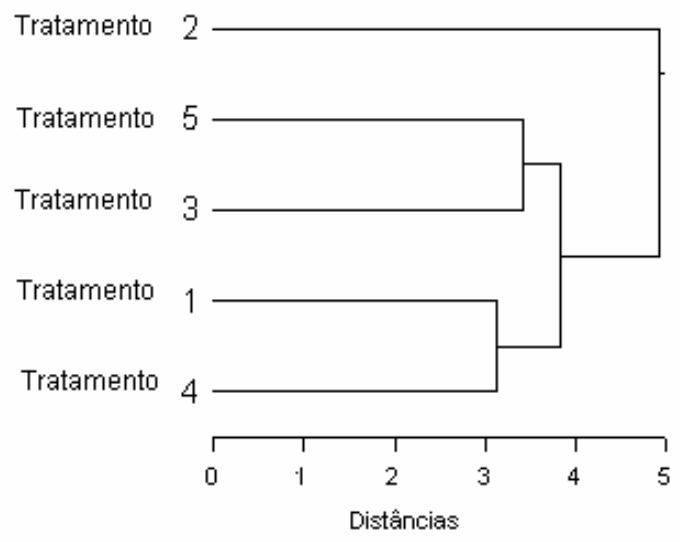

Figura 11 - Fenograma (Distância Média e Método de Ligação Simples) para os parâmetros: resíduo, peso, altura, diâmetro e número de frutos brocados e tratamentos.

A análise de agrupamento (Systat) mostra que o tratamento 2 fica isolado do grupo formado pelos tratamentos 1, 3, 4 e 5 (Figura 11), em relação à todos os parâmetros utilizados, concordando com os resultados obtidos para resíduo (Tabela 7 ).

Tabela 9. Porcentagem de frutos atacados por tratamento

\begin{tabular}{lc}
\hline \multicolumn{1}{c}{ Tratamentos } & $\begin{array}{c}\text { Média do número de frutos } \\
\text { brocados (\%) }\end{array}$ \\
\hline 1-deltametrina/linha simples & $4,89 \mathrm{ab}$ \\
2-carbari//linha simples & $1,34 \mathrm{~b}$ \\
3-deltametrina/linha dupla & $8,00 \mathrm{a}$ \\
4-carbaril/linha dupla & $7,11 \mathrm{a}$ \\
5-testemunha & $10,22 \mathrm{a}$ \\
\hline
\end{tabular}


A eficiência dos tratamentos no controle da broca-pequena-do-fruto esta apresentada na Tabela 9. O tratamento 2 (carbaril/linha simples) foi o que apresentou o melhor controle e não foi significativamente diferente do tratamento 1 (deltametrina/linha simples). A testemunha apresentou maior infestação, porém não diferiu dos demais tratamentos, exceto do 2 (carbaril/linha simples).

Tabela 10. Resíduos de deltametrina em tomate (frutos), nos tratamentos linha simples e linha dupla. Piedade - SP

\begin{tabular}{|c|c|c|c|c|c|}
\hline \multirow{2}{*}{ Tratamento } & \multirow{2}{*}{ DAT } & \multicolumn{3}{|c|}{ Repetições $\mathrm{mg} \mathrm{kg}^{-1}$ (ppm) } & \multirow{2}{*}{$\begin{array}{c}\mathrm{m} \pm \mathrm{s} \\
\mathrm{mg} \cdot \mathrm{kg}^{-1}(\mathrm{ppm})\end{array}$} \\
\hline & & 1 & 2 & 3 & \\
\hline \multirow{5}{*}{ testemunha } & -1 & $<0,01$ & $<0,01$ & $<0,01$ & $<0,01$ \\
\hline & 0 & $<0,01$ & $<0,01$ & $<0,01$ & $<0,01$ \\
\hline & 3 & $<0,01$ & $<0,01$ & $<0,01$ & $<0,01$ \\
\hline & 5 & $<0,01$ & $<0,01$ & $<0,01$ & $<0,01$ \\
\hline & 10 & $<0,01$ & $<0,01$ & $<0,01$ & $<0,01$ \\
\hline \multirow{5}{*}{ linha simples } & -1 & 0,01 & 0,01 & 0,02 & $0,01 \pm 0,00$ \\
\hline & 0 & 0,04 & 0,03 & 0,05 & $0,04 \pm 0,01$ \\
\hline & 3 & 0,05 & 0,06 & 0,04 & $0,05 \pm 0,02$ \\
\hline & 5 & 0,02 & 0,02 & 0,03 & 0,02 \\
\hline & 10 & 0,02 & 0,03 & 0,02 & 0,02 \\
\hline \multirow{5}{*}{ linha dupla } & -1 & 0,01 & 0,01 & 0,00 & $0,01 \pm 0,00$ \\
\hline & 0 & 0,02 & 0,03 & 0,01 & $0,02 \pm 0,01$ \\
\hline & 3 & 0,02 & 0,02 & 0,03 & $0,02 \pm 0,01$ \\
\hline & 5 & 0,03 & 0,02 & 0,02 & 0,02 \\
\hline & 10 & 0,03 & 0,01 & 0,02 & $0,02 \pm 0,01$ \\
\hline
\end{tabular}


Tabela 11. Resíduos de carbaril em tomate (frutos), nos tratamentos linha simples e linha dupla; Piedade - SP

\begin{tabular}{lccccc}
\hline \multirow{2}{*}{ Tratamento } & DAT & \multicolumn{3}{c}{ Repetições $\mathrm{mg}^{\mathrm{kg}} \mathrm{kg}^{-1}(\mathrm{ppm})$} & $\mathrm{m} \pm \mathrm{s}$ \\
\cline { 2 - 5 } & & 1 & 2 & 3 & $\mathrm{mg} \cdot \mathrm{kg}^{-1}(\mathrm{ppm})$ \\
\cline { 2 - 5 } testemunha & -1 & $<0,05$ & $<0,05$ & $<0,05$ & $<0,05$ \\
& 0 & $<0,05$ & $<0,05$ & $<0,05$ & $<0,05$ \\
& 3 & $<0,05$ & $<0,05$ & $<0,05$ & $<0,05$ \\
& 5 & $<0,05$ & $<0,05$ & $<0,05$ & $<0,05$ \\
linha simples & 10 & $<0,05$ & $<0,05$ & $<0,05$ & $<0,05$ \\
& & & & & \\
& -1 & 0,11 & 0,11 & 0,16 & $0,13 \pm 0,12$ \\
& 0 & 1,03 & 1,65 & 1,63 & $1,44 \pm 0,35$ \\
& 3 & 0,82 & 1,28 & 1,70 & $1,27 \pm 0,60$ \\
linha dupla & 5 & 0,67 & 0,76 & 1,24 & $0,89 \pm 0,31$ \\
& 10 & 0,62 & 0,62 & 1,14 & $0,79 \pm 0,30$ \\
& & & & & \\
& -1 & 0,07 & 0,13 & 0,09 & $0,01 \pm 0,00$ \\
& 0 & 0,66 & 0,59 & 0,67 & $0,64 \pm 0,04$ \\
& 3 & 0,51 & 0,56 & 0,48 & $0,52 \pm 0,18$ \\
& 5 & 0,47 & 0,58 & 0,79 & $0,61 \pm 0,16$ \\
& 10 & 0,35 & 0,30 & 0,49 & $0,38 \pm 0,10$ \\
\hline
\end{tabular}

Conforme observa-se na Tabela 10, os resíduos de deltametrina no fruto foram sempre maiores nos tratamentos linha simples, estando abaixo do LMR (0,03 mg. $\left.\mathrm{kg}^{-1}\right)$ apenas com 5 dias após a aplicação, portanto, após o período de carência estabelecido pela ANVISA (3 dias). Nos tratamentos linha dupla (plantio comercial) os resíduos estiveram sempre abaixo do LMR, em qualquer época de amostragem, inclusive no período de carência (3 dias). Baixas concentrações de resíduo de deltametrina na cultura de tomate também foram descritas por Balwinder et al (1989), que concluíram que o uso de 
piretróides sintéticos na cultura do tomate, em condições sub-tropicais, não representava perigo à saúde dos consumidores.

Ripley et al. (2001) encontraram resíduos de permetrina, cipermetrina e deltametrina, em diversas culturas (brócolis, mostarda, repolho, cenoura, berinjela, tomate entre outras) sempre com valores abaixo do LMR e dentro do intervalo de segurança estabelecido. Exceto para fenvalerate, que se apresentou mais persistente especialmente nas culturas onde o LMR era $>0,1$ mg.kg-1.

Assim como nos tratamentos com deltametrina, os resíduos de carbaril nos frutos foram sempre maiores nos tratamentos linha simples, e sempre acima do $\operatorname{LMR}\left(0,1 \mathrm{mg} \cdot \mathrm{kg}^{-1}\right)$, nos dois sistemas de plantio. Nos tratamentos linha dupla, estes se mantiveram constantes nas amostragens realizadas de 0 a 5 dias, decrescendo $36 \%$ com 10 dias após a aplicação. Os resíduos de carbaril mostraram-se superiores aos encontrados por Frank et al. (1991). Esses autores observaram valores de resíduo de carbaril em frutos de tomate menores que $0,1 \mathrm{mg} \cdot \mathrm{kg}^{-1}, 7$ dias após a última aplicação, em experimentos de campo, conduzidos em diversas cidades no Canadá.

A Tabela 9 mostrou que o melhor nível de controle foi conseguido utilizando-se o plantio experimental, para os dois pesticidas. Entretanto, os níveis de resíduo encontrados nos tratamentos com esse plantio estiveram acima do LMR no intervalo de segurança estabelecido pela ANVISA. Assim, observa-se que no plantio comercial (linha dupla) os resíduos tendem a ser menores, oferecendo menor controle da broca-pequena-do-fruto. Coerentemente, maior resíduo (plantio experimental), melhor controle; e, inversamente, menor resíduo (plantio convencional), menor controle, tanto para deltametrina como para carbaril. 
Tabela 12. Resíduos de deltametrina em tomate (folhas), nos tratamentos linha simples e linha dupla; Piedade - SP

\begin{tabular}{lccccc}
\hline \multirow{2}{*}{ Tratamento } & DAT & \multicolumn{3}{c}{ Repetições $\mathrm{mg}_{\mathrm{kg}}^{-1}(\mathrm{ppm})$} & $\mathrm{m} \pm \mathrm{s}$ \\
\cline { 2 - 4 } & & 1 & 2 & 3 & $\mathrm{mg}^{-1}(\mathrm{kpm})$ \\
\hline \multirow{3}{*}{ testemunha } & -1 & $<0,05$ & $<0,05$ & $<0,05$ & $<0,05$ \\
& 0 & $<0,05$ & $<0,05$ & $<0,05$ & $<0,05$ \\
& 1 & $<0,05$ & $<0,05$ & $<0,05$ & $<0,05$ \\
& 3 & $<0,05$ & $<0,05$ & $<0,05$ & $<0,05$ \\
& 10 & $<0,05$ & $<0,05$ & $<0,05$ & $<0,05$ \\
linha simples & 20 & $<0,05$ & $<0,05$ & $<0,05$ & $<0,05$ \\
& & & & & \\
& -1 & 1,08 & 0,76 & 0,77 & $0,87 \pm 0,18$ \\
& 0 & 1,43 & 1,46 & 1,68 & $1,52 \pm 0,14$ \\
& 1 & 1,07 & 1,15 & 1,18 & $1,13 \pm 0,06$ \\
& 3 & 0,78 & 0,80 & 1,12 & $0,90 \pm 0,19$ \\
linha dupla & 10 & 0,74 & 0,83 & 1,08 & $0,88 \pm 0,18$ \\
& 20 & 0,42 & 0,43 & 1,02 & $0,63 \pm 0,34$ \\
& & & & & \\
& -1 & 0,45 & 0,48 & 0,60 & $0,51 \pm 0,08$ \\
& 0 & 1,01 & 0,90 & 1,37 & $1,09 \pm 0,25$ \\
& 1 & 0,94 & 0,93 & 1,08 & $0,98 \pm 0,09$ \\
& 3 & 0,47 & 0,61 & 0,66 & $0,58 \pm 0,10$ \\
& 10 & 0,70 & 0,59 & 0,69 & $0,66 \pm 0,06$ \\
& 20 & 0,51 & 0,29 & 0,59 & $0,46 \pm 0,15$ \\
\hline
\end{tabular}


Tabela 13. Resíduos de carbaril em tomate (folhas), nos tratamentos linha simples e linha dupla; Piedade - SP

\begin{tabular}{lccccc}
\hline \multirow{2}{*}{ Tratamento } & DAT & \multicolumn{3}{c}{ Repetições $\mathrm{mg}_{\mathrm{kg}}^{-1}(\mathrm{ppm})$} & $\mathrm{m} \pm \mathrm{s}$ \\
\cline { 2 - 4 } & & 1 & 2 & 3 & $\mathrm{mg}^{-1}(\mathrm{kpm})$ \\
\hline \multirow{3}{*}{ testemunha } & -1 & $<1,00$ & $<1,00$ & $<1,00$ & $<1,00$ \\
& 0 & $<1,00$ & $<1,00$ & $<1,00$ & $<1,00$ \\
& 1 & $<1,00$ & $<1,00$ & $<1,00$ & $<1,00$ \\
& 3 & $<1,00$ & $<1,00$ & $<1,00$ & $<1,00$ \\
linha simples & 10 & $<1,00$ & $<1,00$ & $<1,00$ & $<1,00$ \\
& 20 & $<1,00$ & $<1,00$ & $<1,00$ & $<1,00$ \\
& & & & & \\
& -1 & 38,90 & 55,50 & 102,18 & $65,53 \pm 32,81$ \\
& 0 & 122,95 & 115,88 & 145,68 & $128,17 \pm 15,57$ \\
& 1 & 109,26 & 107,19 & 142,84 & $119,76 \pm 20,01$ \\
& 3 & 85,67 & 133,01 & 98,59 & $105,75 \pm 24,47$ \\
& 10 & 39,31 & 43,65 & 132,19 & $71,72 \pm 52,42$ \\
& 20 & 34,72 & 45,18 & 44,72 & $41,54 \pm 5,91$ \\
& & & & & \\
& -1 & 36,40 & 23,60 & 61,79 & $40,60 \pm 19,44$ \\
& 0 & 76,09 & 78,90 & 82,63 & $79,21 \pm 3,28$ \\
& 1 & 71,10 & 74,66 & 78,51 & $74,76 \pm 3,71$ \\
& 3 & 38,32 & 59,10 & 67,55 & $54,99 \pm 15,04$ \\
& 10 & 100,65 & 30,20 & 28,05 & $52,96 \pm 41,31$ \\
& 20 & 11,29 & 7,85 & 16,98 & $12,04 \pm 4,61$ \\
\hline
\end{tabular}

Nas folhas, como esperado, os resíduos foram muito maiores do que nos frutos, pelo fato delas acharem-se muito mais expostas durante as operações de pulverização(ões), além de terem as folhas superfícies específicas muito maiores do que os frutos.

O tratamento linha simples deltametrina apresentou valores de resíduos variando entre 1,52 a $0,63 \mathrm{mg} \cdot \mathrm{kg}^{-1}$, com zero e 20 dias respectivamente, e decrescendo $59 \%$ ao final do período de observação de 20 
dias. Para o tratamento linha dupla os resíduos variaram entre 1,09 e 0,46 mg. $\mathrm{kg}^{-1}$, com zero e 20 dias respectivamente, e descresceram na mesma proporção ao tratamento linha simples (58\%) com 20 dias (Tabela 12).

Os resultados com carbaril (Tabela 13) mostram que seus resíduos foram encontrados em níveis numericamente bem maiores do que os de deltametrina, certamente, em razão do uso de maior quantidade do ingrediente ativo na calda de pulverização. De qualquer modo, nesse caso, os dados tiveram grande variabilidade em alguns casos, indicando, talvez, necessidade de amostragem de maior quantidade de material.

As concentrações de carbaril no tratamento linha simples variaram de 128,17 a $41,54 \mathrm{mg} \cdot \mathrm{kg}^{-1}$, com zero e 20 dias respectivamente, decrescendo $68 \%$ nesse período. Enquanto que, no linha dupla variaram de 79,21 a 12,04 no mesmo período, decrescendo $84 \%$ (Tabela 13).

Os resíduos de carbaril e deltametrina nas folhas foram sempre maiores nos tratamentos linha simples, fato esperado, uma vez que o mesmo volume de calda é aplicado num número menor de plantas. 
Tabela 14. Resíduos de deltametrina no solo, nos tratamentos linha simples e linha dupla; Piedade - SP

\begin{tabular}{|c|c|c|c|c|c|}
\hline \multirow{2}{*}{ Tratamento } & \multirow{2}{*}{ DAT } & \multicolumn{3}{|c|}{ Repetições $\mathrm{mg} \mathrm{kg}^{-1}$ (ppm) } & \multirow{2}{*}{$\begin{array}{c}\mathrm{m} \pm \mathrm{s} \\
\mathrm{mg} \cdot \mathrm{kg}^{-1}(\mathrm{ppm})\end{array}$} \\
\hline & & 1 & 2 & 3 & \\
\hline \multirow{6}{*}{ testemunha } & -1 & $<0,005$ & $<0,005$ & $<0,005$ & $<0,005$ \\
\hline & 0 & $<0,005$ & $<0,005$ & $<0,005$ & $<0,005$ \\
\hline & 1 & $<0,005$ & $<0,005$ & $<0,005$ & $<0,005$ \\
\hline & 3 & $<0,005$ & $<0,005$ & $<0,005$ & $<0,005$ \\
\hline & 10 & $<0,005$ & $<0,005$ & $<0,005$ & $<0,005$ \\
\hline & 20 & $<0,005$ & $<0,005$ & $<0,005$ & $<0,005$ \\
\hline \multirow{6}{*}{ linha simples } & -1 & 0,01 & 0,02 & 0,05 & $0,03 \pm 0,02$ \\
\hline & 0 & 0,04 & 0,01 & 0,06 & $0,04 \pm 0,02$ \\
\hline & 1 & 0,02 & 0,01 & 0,03 & $0,02 \pm 0,01$ \\
\hline & 3 & 0,02 & 0,01 & 0,03 & $0,02 \pm 0,01$ \\
\hline & 10 & 0,01 & 0,00 & 0,08 & $0,03 \pm 0,04$ \\
\hline & 20 & 0,01 & 0,00 & 0,10 & $0,04 \pm 0,06$ \\
\hline \multirow{6}{*}{ linha dupla } & -1 & 0,01 & 0,02 & 0,02 & $0,02 \pm 0,01$ \\
\hline & 0 & 0,01 & 0,02 & 0,02 & $0,02 \pm 0,01$ \\
\hline & 1 & 0,01 & 0,02 & 0,06 & $0,03 \pm 0,02$ \\
\hline & 3 & 0,04 & 0,01 & 0,01 & $0,02 \pm 0,01$ \\
\hline & 10 & 0,00 & 0,02 & 0,06 & $0,03 \pm 0,03$ \\
\hline & 20 & 0,02 & 0,01 & 0,01 & $0,02 \pm 0,00$ \\
\hline
\end{tabular}


Tabela 15. Resíduos de carbaril no solo, nos tratamentos linha simples e linha dupla; Piedade - SP

\begin{tabular}{|c|c|c|c|c|c|}
\hline \multirow{2}{*}{ Tratamento } & \multirow{2}{*}{ DAT } & \multicolumn{3}{|c|}{ Repetições $\mathrm{mg} \cdot \mathrm{kg}^{-1}(\mathrm{ppm})$} & \multirow{2}{*}{$\begin{array}{c}\mathrm{m} \pm \mathrm{s} \\
\mathrm{mg} \cdot \mathrm{kg}^{-1}(\mathrm{ppm})\end{array}$} \\
\hline & & 1 & 2 & 3 & \\
\hline \multirow{6}{*}{ testemunha } & -1 & $<0,01$ & $<0,01$ & $<0,01$ & $<0,01$ \\
\hline & 0 & $<0,01$ & $<0,01$ & $<0,01$ & $<0,01$ \\
\hline & 1 & $<0,01$ & $<0,01$ & $<0,01$ & $<0,01$ \\
\hline & 3 & $<0,01$ & $<0,01$ & $<0,01$ & $<0,01$ \\
\hline & 10 & $<0,01$ & $<0,01$ & $<0,01$ & $<0,01$ \\
\hline & 20 & $<0,01$ & $<0,01$ & $<0,01$ & $<0,01$ \\
\hline \multirow{6}{*}{ linha simples } & -1 & 0,03 & 0,00 & 0,09 & $0,04 \pm 0,04$ \\
\hline & 0 & 0,09 & 0,09 & 0,12 & $0,10 \pm 0,02$ \\
\hline & 1 & 0,07 & 0,34 & 0,13 & $0,18 \pm 0,14$ \\
\hline & 3 & 0,04 & 0,04 & 0,14 & $0,07 \pm 0,06$ \\
\hline & 10 & 0,02 & 0,01 & 0,03 & $0,02 \pm 0,01$ \\
\hline & 20 & 0,03 & 0,04 & 0,02 & $0,03 \pm 0,01$ \\
\hline \multirow{6}{*}{ linha dupla } & -1 & 0,01 & 0,02 & 0,02 & $0,02 \pm 0,01$ \\
\hline & 0 & 0,09 & 0,12 & 0,19 & $0,13 \pm 0,05$ \\
\hline & 1 & 0,03 & 0,12 & 0,23 & $0,13 \pm 0,10$ \\
\hline & 3 & 0,06 & 0,09 & 0,09 & $0,08 \pm 0,02$ \\
\hline & 10 & 0,03 & 0,01 & 0,09 & $0,04 \pm 0,04$ \\
\hline & 20 & 0,03 & 0,00 & 0,02 & $0,02 \pm 0,01$ \\
\hline
\end{tabular}

As Tabelas 14 (deltametrina) e 15 (carbaril) mostram os resíduos dos pesticidas nos solos. Os valores encontrados para deltametrina (Tabela 14) foram baixos e muito próximos aos encontrados nos frutos. No caso do carbaril (Tabela 15) eles estavam abaixo dos encontrados nos frutos. Os resíduos no solo não variaram muito durante todo período de amostragem, mostrando assim, que houve baixo escorrimento da calda de saturação, causando eles, assim, baixa contaminação nesse recurso natural, comparado à introdução 
pelos restos vegetais da cultura (resíduo nas folhas) que apresentam, teoricamente, maior potencial nesse aspecto.

Em todos os casos os resíduos nas amostras testemunhas, para os dois pesticidas em todos os substratos (fruto, folha e solo), estiveram sempre abaixo dos respectivos LOQs, o que revela estarem as parcelas testemunhas muito bem protegidas contra a contaminação cruzada de deriva das aplicações, o que é, por vezes, de difícil garantia.

Os dados climáticos obtidos da região na época do experimento não sugeriram interferências nos resíduos encontrados nos três substratos. 


\section{CONCLUSÕES}

A análise dos resultados obtidos, nas condições em que foi realizado o experimento, permite concluir que:

- o inseticida deltametrina quando usado como recomendado não apresenta riscos à saúde dos consumidores, pois seus resíduos nos frutos no plantio comercial, apresentaram-se abaixo do LMR durante todo o intervalo de segurança, estabelecidos pela ANVISA; o mesmo não ocorreu com o carbaril que nos dois sistemas de condução apresentou resíduos superiores ao LMR;

- os resíduos mais altos foram encontrados nas folhas, tanto para deltametrina como para carbaril, sendo, assim, consideradas estas uma possível fonte de contaminação ambiental;

- os resíduos encontrados no solo foram baixos, e no caso da deltametrina se aproximaram dos valores encontrados para o fruto, sendo os de carbaril ainda menores que os do fruto, mostrando um baixo escorrimento da calda de saturação e conseqüentemente, um baixo potencial de introdução de pesticidas no ambiente;

- o plantio experimental (linha simples) apresentou concentrações de resíduos sempre maiores, comparadas ao plantio comercial (linha dupla), sendo, ainda, os níveis de controle da praga melhores nesses tratamentos. 


\section{REFERÊNCIAS BIBLIOGRÁFICAS}

ANDERSSON, A.; PALSHEDEN, H. Multi-residue method for the analysis of pesticides in fruit and vegetables using ethyl acetate extraction, GPC clean-up and GC determination. In: NATIONAL FOOD ADMINISTRATION. Pesticide analytical methods in Sweden. Uppsala: Rapport, 1998. p. 9-41.

ANDREI, E. Compêndio de defensivos agrícolas. São Paulo: ANDREI, 1996. 506p.

AGÊNCIA NACIONAL DE VIGILÂNCIA SANITÁRIA.carbaril http://www4.anvisa.gov.br/AGROSIA/asp/frm_dados_ingrediente.asp?iVarAu $x=1 \&$ Codlng=73 (13 out. 2003).

AGÊNCIA NACIONAL DE VIGILÂNCIA SANITÁRIA.deltametrina.

http://www4.ANVISA.gov.br/AGROSIA/asp/frm_dados_ingrediente.asp?iVar Aux=1\&Codlng=124 (13 out. 2003).

AWASTHI, M. D.; Soil retention and plant uptake of soil apllied granular phorate and carbaril. Indian Journal of Plant Protection, v. 18, n.2, p. 219-223, 1999. Resumo em CAB Abstracts, v.18, n.2, p.219, 1990/1991. 
BALWINDER, S.; PARM. P. S.; RAMINDERJIT, S. B.; KALRA, R. L. Residues of synthetic pyrethroid insecticides on tomato under sub-tropical conditions of Punjab, India. Bulletin of Environmental Contamination and Toxicology, v. 43 , n. 5, p.733-736, 1989. Resumo em CAB Abstract, v.18, n.2, p.219, 1990-1991.

BIAGGI, E. Manual da cultura do tomate. São Paulo: Biaggi, 1977. 164p.

CARDOSO, D. Empresa de Israel compra a Milenia. Gazeta Mercantil (Caderno de finanças e Mercados), São Paulo, 19 fev. 2002, p. B-16.

CIIAGRO

http://www.iac.sp.gov.br/New/ciiagro/ (10 dez. 2003).

FERNANDES, O.A.; CARDOSO A. M.; MARTINELLI, S. Manejo integrado de pragas do tomate: reconhecimento das pragas e táticas de controle. FUNEP. Jaboticabal, SP. 2003.39p.

FNP CONSULTORIA \& COMÉRCIO. Agrianual 2002 anuário da agricultura brasileira. São Paulo, 2003. p.310.

FRANK, R.; BRAUN, H. E. ; PITBLADO, R. Residues of none insecticidas and two fungicides in raw and processed tomatoes. Journal of Food Protection, v. 54, n. 1, p. 41-46, 1991.

GALLO, D.; NAKANO, O.; NETO, S. S.; CARVALHO, R. P. L.; BAPTISTA, G. C.; FILHO, E. B.; PARRA, J. R. P.; ZUCCHI, R. A.; ALVES, S. B.; VENDRAMIM, J. D.; MARCHINI, L. C.; LOPES, J. R. S.; OMOTO, C. Entomologia Agrícola. Piracicaba: FEALQ, 2002. 920p. 
GOPICHAND, K.; BABU, T. R.; REDDY, D. D. R.; GOUR, T. B. Dissipation and decontamination of monocrotophos and carbaril residues in tomato. Journal of Research ANGRAU, v. 26, n. 2, p. 13-16, $1998 . \quad$ Resumo em CAB Abstracts, 1998/2000.

GRAVENA, S. \& S. A. DE BORTOLI. Manejo Integrado de Pragas do Tomateiro (Boletim Técnico). Jaboticabal: FCAV/UNESP, 1986. 64p.

MINAMI, K.; HAAG, H. P. O Tomateiro. Campinas: Fundação Cargil, 1989. $352 p$.

MIRANDA, G. M. C. Importância da cultura do tomateiro. In: MIRANDA, G.M. C. Cenário Futuro do Negócio Agrícola de Minas Gerais - Cenário Futuro Para a Cadeia Produtiva de Olerícolas Em Minas Gerais. 1995. v.1, p. $48-68$.

PREM, C.; KASHYAP, N. P.; JITENDER, K.; CHAND, P.; KUMAR, J. Residue dynamics of some insecticides on/in tomato, Lycopersicon esculentum Mill. Pest Management and Economic Zoology, v. 7, n. 2, p. 131-135, 1999. Resumo em CAB Abstracts, v. 7, n.2, p. 131, 2000/2002.

RIPLEY, B. D.; RITCEY, G. M.; HARRIS, C. R.; DENOMME, M. A.; BROWN, P. D. Pyrethroid insecticide residues on vegetable crops. Pest Management Science, v.57, n. 8, p. 683-687, 2001.

SALDIVAR, E. L. Pesticide usage and residues on vegetables, grains and fruits. Philippine Journal of Crop Science, v. 23, n. 1, p. 37, $1998 . \quad$ Resumo em AGRIS, 1997/1998. 
TOMLIN, C. The Pesticide Manual. Surrey: The Royal Society of Chemistry, 1995. $1341 \mathrm{p}$. 